\title{
A Comprehensive Characterization of Different Fractions of Corn Stover and Their Relationships to Multipollutant Sorption Characteristics
}

\author{
Dan Peng $\mathbb{D}^{1},{ }^{1}$ Fan Ouyang, ${ }^{1}$ Min Deng $\mathbb{D},{ }^{2}$ Lei Nie, ${ }^{1}$ and Sifang Kong ${ }^{1}$ \\ ${ }^{1}$ Department of Transportation and Environment, Shenzhen Institute of Information Technology, Shenzhen 518172, China \\ ${ }^{2}$ Institute of Occupational Hazard Assessment, Shenzhen Prevention and Treatment Center for Occupational Disease, \\ Shenzhen 518020, China \\ Correspondence should be addressed to Min Deng; keydm@163.com
}

Received 5 March 2021; Accepted 23 July 2021; Published 6 August 2021

Academic Editor: Xue Tao Guo

Copyright (c) 2021 Dan Peng et al. This is an open access article distributed under the Creative Commons Attribution License, which permits unrestricted use, distribution, and reproduction in any medium, provided the original work is properly cited.

Corn stover (CS) is mainly composed of three parts: pith (CSP), rind (CSR), and leaf (CSL). These parts have different lignocellulosic constituents and structural properties. Herein, biosorbents derived from individual corn stover constituents were prepared in an effort to determine the significance of each constituent for multipollutant removal. In this study, SEM, BET, XRD, FTIR, XPS, fibre composition, and contact angle measurements were used to characterize and analyse the physical and chemical properties of the three components of CS and to study their adsorption effects, adsorption isotherms, and kinetics. The lignocellulosic compositions of CSP and CSR were similar, the cellulose content in CSP and CSR was significantly higher than that in CSL, and the hemicellulose content of CSL was much higher than those of CSP and CSR. The minimum lignin content was found in CSP, and the maximum lignin content was found in CSR. The results show that each component had a certain adsorption effect on typical organic pollutants (antibiotics, oils, and dyes). CSP had the strongest oil adsorption capacity, CSR was more suitable for adsorbing antibiotics, and CSL had outstanding adsorption capacity for dye. The pseudo-second-order model and the Langmuir adsorption isotherm model could describe the adsorption processes well, and they consisted of monolayer adsorption accompanied by chemical adsorption reactions. The focus of this study was to provide references for selecting effective adsorbent precursors to remove organic pollutants from wastewater.

\section{Introduction}

In recent decades, many pollutants have been produced worldwide due to the development of industrialized economies and growth in populations. Organic matter is widely used, so organic pollution in the water environment is a serious issue. Among these organics, oils, antibiotics, and dyes are most commonly found. Oil spills occur during natural seepage, extraction, transportation, refining, and consumption [1]. An oil layer on water surfaces hinders photosynthesis and oxygen exchange, causes harm to aquatic animals and plants, affects human activities and health, and may even cause cancer and mutagenicity in humans. Antibiotics are commonly used in humans and veterinary medicine to treat diseases and to promote the growth of aquaculture and live- stock $[2,3]$; however, they are only partially metabolized in organisms, so up to $80-90 \%$ of the parent compounds and/or metabolites are excreted [4]. These compounds may enter the environment through the application of biosolid manure in farmland, grazing of livestock, or discharge of wastewater $[5,6]$. Based on market sales data, China is the largest producer and user of antibiotics in the world [7]. According to a study, 54,000 tons of antibiotics are excreted by humans and animals each year, and nearly 53,800 tons end up in the receiving environment [8]. Therefore, the current situation for pollution is not encouraging. Organic dyes are also used in many industries, such as textiles, paints, printing, and plastics. It is estimated that more than 10,000 kinds of commercial dyes are produced annually, totaling more than $7 \times 10^{5}$ tons [9]. The discharge of these toxic pollutants into 
natural water bodies can seriously threaten the ecological balance and cause harm to flora and fauna [10].

Many methods have been established for the removal of organic pollutants, such as oxidation [11], precipitation [12], adsorption [13], electrochemical techniques [14], and ion exchange [15]. Adsorption has been considered a promising method for removing contaminants due to comprehensive economic and environmental considerations [16]. Therefore, it is of great significance to develop a low-cost and efficient adsorbent for the removal of organic pollutants from wastewater.

Agricultural waste has always received extra attention because it is an attractive starting precursor because of its abundance, low-cost, biodegradable properties, and special structures, such as its large specific surface area, unique porosity, and rich functional groups in pores [17]. Agricultural wastes can be used in their natural form or modified with various treatments [18]. The chemical composition, morphological structure, and mechanical properties of biomass are essential criteria for selecting the best lignocellulose material $[19,20]$.

The production level of corn is one of the largest among the crops in the world and can result in a large quantity of stover waste after harvest. In developing countries, most of the stover is disposed of by direct dumping or burning in the field without effective utilization, which causes serious air pollution, such as haze, and damage to the land and the surrounding area [21-24]. This is a threat to the ecological environment. However, corn stover is a good resource for many fields, such as the paper industry [25], building material industry [26], adsorption material industry [27], and biofuel industry [28]. As an agricultural waste, corn stover is a promising resource for environmental technology used in the treatment of wastewater, since it is rich in cellulose, hemicellulose, and lignin, and the availability of specific functional groups (such as hydroxyl $(-\mathrm{OH})$ ) offers the potential to use them as adsorbents [29].

Corn stover has been used to effectively remove many contaminants, such as oil [30], metal ions [31], dyes [32], and other organics [33]. Previous studies indicated that the adsorption capacity of raw corn stover for dye reaches $4 \mathrm{gg}^{-1}$ and approximately $4.3 \mathrm{gg}^{-1}$ for gas oil [34]. The maximum level of removal of emulsified oil by raw corn husk, 56.33\%, was achieved with a contact time of $60 \mathrm{~min}$, a $\mathrm{pH}$ of 7-8, and a dose of $10 \mathrm{mLL}^{-1}$ at $150 \mathrm{rpm}$. To date, however, corn stover is often used in whole form as a raw material for adsorbents. Different biomasses have different microstructures and physicochemical properties, and even the same biomass with different tissues and fractions has different microstructures and physicochemical properties, which can significantly influence adsorption capacities. Corn stover is mainly composed of three parts: the pith, rind, and leaves. Each part has different tissues, cell morphologies, and chemical compositions. The structure, composition, and characteristics of different parts of the corn stover cause unpredictable adsorption performance due to the different types of tissues and organs [35]. For instance, a study has shown that raw corn stalk has a lower capacity for $\mathrm{Cu}$ (II) ions than raw corn cob $\left(0.113 \mathrm{mmolg}^{-1}\right)$ [36]. To effectively utilize agricultural waste and to generate larger economic benefits, each of the different parts of corn stover must be considered.

So far, there is insufficient research on the applications of corn polymers, fibres, and composites, with no study conducted on the impact of the physical, morphological, and mechanical properties of corn stover biomass on organic pollutant adsorption. The aim of this work is to report the characterization of the various natural parts of corn stover with the aim of exploring their potential in the development of biosorbents to remove antibiotics (sulfadiazine (SD)), oil (machine oil (MO)), and dyes (methylene blue (MB)) (Figure 1) from an aqueous solution. The main goal of this study is to observe the structural differences of the raw corn stover pith, rind, and leaf through characterizations, to help increase their utilization rates under realistic conditions, and to discuss their adsorption performances by studying the influence of contact time and initial concentration on the adsorption efficiencies for typical organic pollutants on corn straw. The adsorption kinetics and equilibrium isotherms were studied to analyse the adsorption mechanism. This research may provide valuable information on the physical and chemical characteristics and adsorption properties of different tissue fractions in corn stover and allow further application.

\section{Materials and Experimental Methods}

2.1. Preparation of Materials. Corn stover was gathered from a farm located in Baise city, Guangxi province, China. The raw materials were cleaned with water and dehydrated in direct sunlight. The pith, rind, and leaf were manually separated from the corn stover and then converted to powdered materials by grinding and sieving, and these were named CSP, CSR, and CSL, respectively. The fractions with particle sizes passing through 20- and 60-mesh sieves were dried in an oven at $60^{\circ} \mathrm{C}$ for $24 \mathrm{~h}$ and used for subsequent analysis and experiments.

Sulfadiazine, acetonitrile, and methanol were used as HPLC grade. The oil was purchased from Shell Helix (HX7 $5 \mathrm{~W}-40$ ), with a density of $0.843 \mathrm{~g} \mathrm{~cm}^{-3}$ and a viscosity of $14.45 \mathrm{cp}$ at $20^{\circ} \mathrm{C}$. The other chemicals involved in these experiments were purchased from Sigma-Aldrich. The Milli-Q water was utilized $(18.2 \mathrm{M} \Omega-\mathrm{cm})$.

2.2. Chemical Composition Analysis. The chemical constituents of CSP, CSR, and CSL were determined using ASTM standard methods. Cellulose (ASTM D 1103-55T), hemicellulose (ASTM D 1104-56), and lignin (ASTM D 1106-56) were studied [37].

2.3. Characterization. Scanning electron microscopy (SEM) (Gemini SEM 300, ZEISS, Germany) was used to characterize the surface morphology of the corn stover pith, rind, and leaf at different magnifications. An ASAP 2020 instrument (Micromeritics, USA) running at $77 \mathrm{~K}$ was used to determine the BET surface area and pore size of the samples from nitrogen adsorption isotherms. The tests used the BET formula, $t$ -plot formula, and Barrett-Joyner-Halenda (BJH) formula to obtain the surface areas, total pore volumes, and average pore 

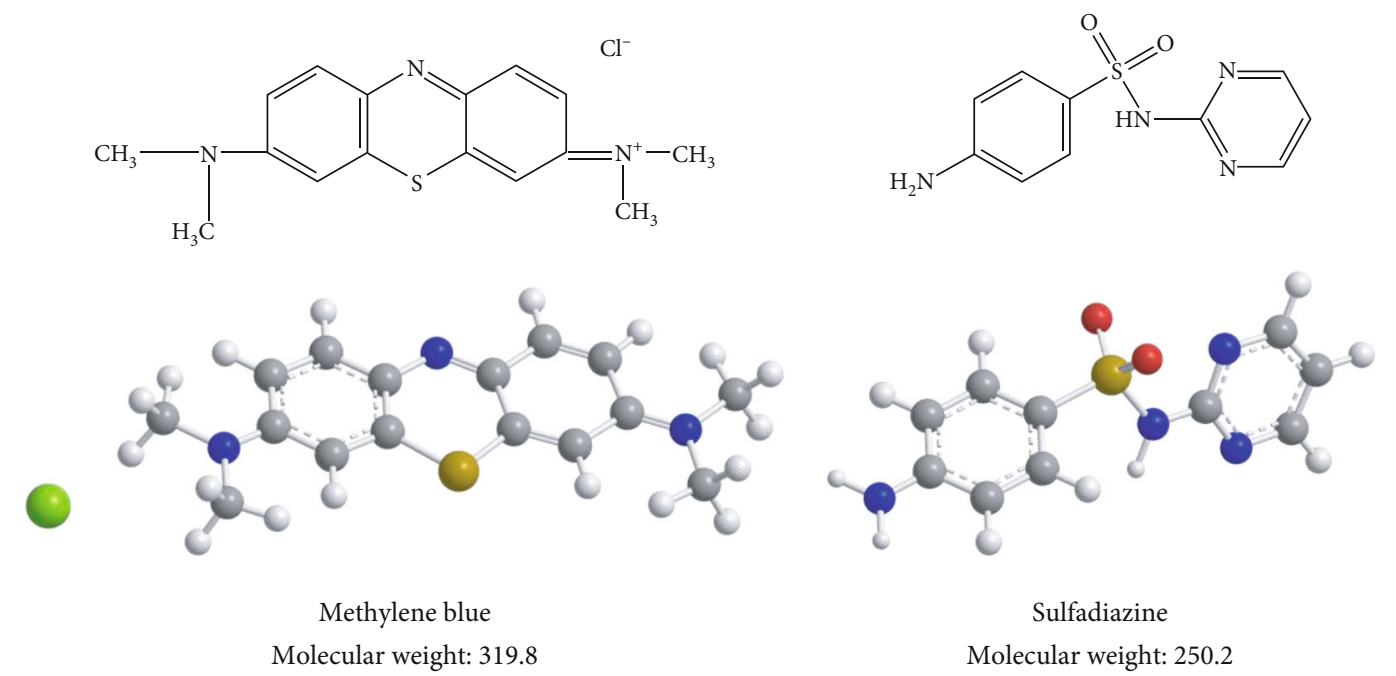

Figure 1: Methylene blue and sulfadiazine structural models.

sizes. Fourier transform infrared spectrometry (FTIR) (Vetex70, Bruker, Germany) was used to analyse the functional groups of samples in the range of $4000-400 \mathrm{~cm}^{-1}$ with a spectral resolution of $4 \mathrm{~cm}^{-1}$. Each sample was analysed by $\mathrm{X}$-ray photoelectron spectroscopy (XPS, Thermo ESCALAB 250) using $\mathrm{Al} \mathrm{K} \alpha$ radiation. The $\mathrm{C} 1 \mathrm{~s}$ and $\mathrm{N} 1 \mathrm{~s}$ photoelectron lines were recorded and calibrated with respect to the $\mathrm{C} 1 \mathrm{~s}$ band at $285.0 \mathrm{eV}$.

The crystal structures of the three samples were measured by X-ray diffraction (XRD) (D8 ADVANCE, Bruker, Germany) using a $\mathrm{Cu}$ target with an incident wavelength of $0.154056 \mathrm{~nm}$, scanning range of $5-60^{\circ}$ and speed of $2^{\circ} / \mathrm{min}$. The crystallinity index (CrI) is a parameter commonly used to quantify the proportion of crystallization area in cellulosic materials and was determined with the following equation [38]:

$$
\mathrm{CrI}=\frac{I_{002}-I_{\mathrm{am}}}{I_{002}} \times 100 \%,
$$

where $I_{002}$ is the intensity of the diffraction peak for the cellulose crystalline region and $I_{\mathrm{am}}$ is the intensity of the diffraction peak $(2 \theta)$ for the amorphous region.

The contact angles (CA) on the surfaces of the samples were measured with a dynamic contact angle analyser (OCA15EC, Data physics, Germany). The water contact angle (WCA) and the oil contact angle (OCA) were determined by the sessile drop method. Briefly, the sieved sample was adhered to the surface of a glass sheet with double-sided tape to obtain a uniform covering. After dripping $5 \mu \mathrm{L}$ of water or oil droplets onto different positions of the corn stover specimens, the contact angles were automatically calculated with the circle fitting method.

\subsection{Sorption Experiments}

2.4.1. Antibiotic Sorption. Sulfadiazine is poorly soluble in water (the solubility is $200 \mathrm{mg} / 100 \mathrm{~mL}$ at $37^{\circ} \mathrm{C}$ ). To ensure the accuracy and reliability of the test data, a stock solution of sulfadiazine $\left(100 \mathrm{mg} \mathrm{L}^{-1}\right)$ was prepared in methanol prior to use. All the batches of test solutions were prepared with the stock solution and transferred to $25 \mathrm{~mL}$ glass vials equipped with screw caps for sorption. In each test, a $10 \mathrm{~mL}$ aliquot of the antibiotic solution was placed in a $25 \mathrm{~mL}$ chromatographic sample bottle containing a $0.01 \mathrm{~g}$ sorbent. The vials were sealed immediately with a cap and placed on a shaker, then agitated at $150 \mathrm{rpm}$ at $25^{\circ} \mathrm{C}$ for $24 \mathrm{~h}$. The mixture in each bottle was immediately filtered through a $0.22 \mu \mathrm{m}$ membrane (Millipore Co.) with a syringe to analyse the concentration by HPLC (Agilent 1100, USA). Formic acid $(v / v)$ $(0.1 \%)$ and acetonitrile were used as the mobile phases, and the ratio was $30: 70$. The flow rate was $1 \mathrm{~mL} \mathrm{~min}^{-1}$, and the column temperature was set at $30^{\circ} \mathrm{C}$. In the kinetic experiments, the initial concentrations of sulfadiazine were $1 \mathrm{mg} \mathrm{L}^{-1}$ and $10 \mathrm{mg} \mathrm{L}^{-1}$, and the preset time was $2-48 \mathrm{~h}$. In the sorption isotherm experiments, the concentrations of sulfadiazine were in the range of $0.5-20 \mathrm{mg} \mathrm{L}^{-1}$. The formula for calculation of sorption capacity was as follows:

$$
q_{e}=\frac{\left(C_{0}-C_{e}\right) V}{m},
$$

where $C_{0}$ and $C_{e}\left(\mathrm{mg} \mathrm{L}^{-1}\right)$ are the initial and equilibrium concentrations of $\mathrm{SD}$, respectively; $V(\mathrm{~mL})$ is the volume of $\mathrm{SD}$ solution; and $m(\mathrm{~g})$ is the mass of the sorbent used.

2.4.2. Water and Oil Sorption. The sorption of oils, as well as water, by various tissue fractions, was studied according to the following procedure. The artificial oil spill was simulated by adding $150 \mathrm{~mL}$ of distilled water and a quantity of motor oil to a $250 \mathrm{~mL}$ glass beaker. Each tested sample $(0.05 \mathrm{~g})$ was put into a preweighed and labelled filter bag, sealed with hot melting, and then put into the solution. After the sorption was complete, the filter bag was lifted for $3 \mathrm{~min}$ to extract excess oil and then weighed. The sorption capacity per unit mass of adsorbent $\left(\mathrm{gg}^{-1}\right)$ was calculated with the following expression: 
TABLE 1: Sorption kinetic model expressions and parameter definitions.

\begin{tabular}{|c|c|c|}
\hline \multicolumn{2}{|c|}{ Nonlinear model (Equations (4), (5), (6), (7)) } & Parameters \\
\hline \multicolumn{3}{|c|}{ The pseudo-first-order model $\quad q_{t}=q_{e}\left(1-e^{-k_{1} t}\right)$} \\
\hline The pseudo-second-order model & $q_{t}=k_{2} q_{e}^{2} t / 1+q_{e} k_{2} t$ & $\begin{array}{c}q_{e}, q_{t}: \text { the amounts of adsorbed adsorbate at equilibrium and at time } t \text {, } \\
\text { respectively; }\end{array}$ \\
\hline Elovich model & $d q_{t} / d t=\alpha \exp \left(-\beta \beta_{t}\right)$ & $k_{1}, k_{2}$ : the rate constants of pseudo-first-order and pseudo-second-order \\
\hline The intraparticle diffusion model & $q_{t}=k_{i} t^{0.5}+C$ & $\begin{array}{c}\text { rate equations, respectively; } \\
\alpha: \text { the initial adsorption rate constant; }\end{array}$ \\
\hline \multicolumn{2}{|c|}{ Linear model (Equations (8), (9), (10)) } & $\beta$ : a parameter related to the degree of surface coverage of the \\
\hline The pseudo-first-order model & $\ln \left(q_{e}-q_{t}\right)=\ln \left(q_{e}\right)-k_{1} t$ & adsorbent and the chemisorption activation energy; \\
\hline The pseudo-second-order model & $t / q_{t}=\left(1 / k_{2} q_{e}^{2}\right)+\left(t / q_{e}\right)$ & $\begin{array}{l}k_{i} \text { : the intraparticle diffusion rate constant determined from the } \\
\text { slope of the plot } q \text { versus } t^{0.5}\end{array}$ \\
\hline Elovich model & $q_{t}=(1 / \beta) \ln (\alpha \beta)+(1 / \beta) \ln t$ & \\
\hline
\end{tabular}

$$
q_{e}=\frac{M-M_{0}}{M_{0}},
$$

where $M_{0}$ and $M$ are the weights of the samples before and after sorption, respectively.

2.4.3. Dye Sorption. A stock solution of $\mathrm{MB}\left(1000 \mathrm{mg} \mathrm{L}^{-1}\right)$ was prepared, and the working solution was serially diluted during the experiments. In all batch sorption experiments, $0.01 \mathrm{~g}$ of adsorbent was placed in a centrifuge tube containing $50 \mathrm{~mL}$ of $\mathrm{MB}$ solution, which was stirred on a shaker at $150 \mathrm{rpm}$ for a specific test time. The initial concentration of $\mathrm{MB}$ used for the sorption kinetic study was $100 \mathrm{mg} \mathrm{L}^{-1}$. The effect of the initial concentration of methylene blue was studied over the range of $25-300 \mathrm{mg} \mathrm{L}^{-1}$. After sorption, the solutions were centrifuged at $10,000 \mathrm{rpm}$ for $15 \mathrm{~min}$, and the supernatants were analysed at $665 \mathrm{~nm}$ using a UVvisible spectrophotometer (Shimadzu UV-2600, Japan). The calculation method for adsorption capacity is the same as formula (2).

2.5. Sorption Kinetic Models. To determine possible mechanisms and the effects of rate-controlling steps on the sorption, CSP, CSR, and CSL were contacted with pollutants at different intervals, and then, the sorption kinetics were studied. Four models were used to describe the time dependence of organic contaminant adsorption onto the samples. The expressions and parameter definitions are shown in Table 1. The Lagergren pseudo-first-order kinetic model is one of the most commonly used equations for describing the physical adsorption process of adsorbents in an aqueous solution $[19,20]$. The pseudo-second-order model is consistent with chemical adsorption being the rate-controlling step. Elovich assumed that the active sites of the adsorbent are heterogeneous and therefore exhibit different activation energies for chemisorption [39]. Intraparticle diffusion (usually the rate controlling step) is a possible method for moving ions from solution onto an adsorbent, and it describes the process of pollutant adsorption in the pores of the sample [40].

2.6. Sorption Equilibrium Isotherms. The sorption isotherm model provides effective information about the mechanism of adsorption, the surface properties of the adsorbent, and the affinity between the adsorbent and the adsorbate. The most frequently utilized models are the Langmuir and Freundlich adsorption isotherms. The Langmuir isotherm model explains monolayer homogeneous sorption based on the assumption of a fixed number of sorption sites, and each site can hold only one sorbate molecule (the sorbed layer is one molecule in thickness). All sites are equivalent, and there is no interaction between the sorbed molecules [36]. The Langmuir model can be described with the following equation:

$$
\frac{1}{q_{e}}=\frac{1}{K_{L} q_{m}} \frac{1}{C_{e}}+\frac{1}{q_{m}}
$$

where $q_{m}$ is the maximum adsorption capacity $\left(\mathrm{mgg}^{-1}\right)$ and $K_{L}$ is the Langmuir adsorption equilibrium constant $\left(\mathrm{L} \mathrm{mg}^{-1}\right)$.

The Freundlich isotherm model is an experimental model, usually expressed by the following equation:

$$
q_{e}=K_{f} \times\left(C_{e}\right)^{1 / n}
$$

It can also be expressed in a logarithmic form as the following equation:

$$
\ln q_{e}=\frac{1}{n} \ln C_{e}+\ln K_{f}
$$

where $K_{f}$ is the Freundlich constant $\left(\mathrm{mgg}^{-1}\right)$ and $n$ is an empirical parameter of change.

\section{Results and Discussion}

\subsection{Effect of Fractionation on the Physiochemical Properties of Corn Stover}

3.1.1. Compositions of Corn Stover Fibres. Based on the structures, corn stover can be divided into the leaf, rind, and pith. Through observation and composition analysis, it was found that the structures and chemical compositions of the parts are different (Figure 2(a)). The CSP structure is made of flexible material wrapped with long fibres, and it is very light. CSR has the highest mechanical strength. The structures of CSR and CSL are compact, mostly in the form 


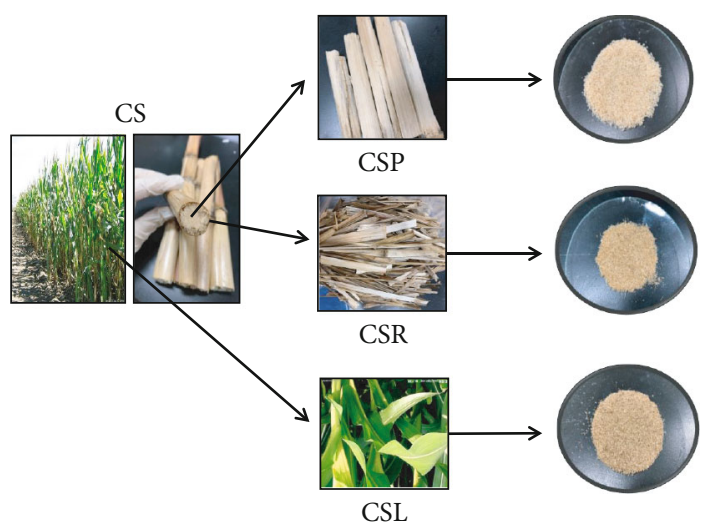

CSL

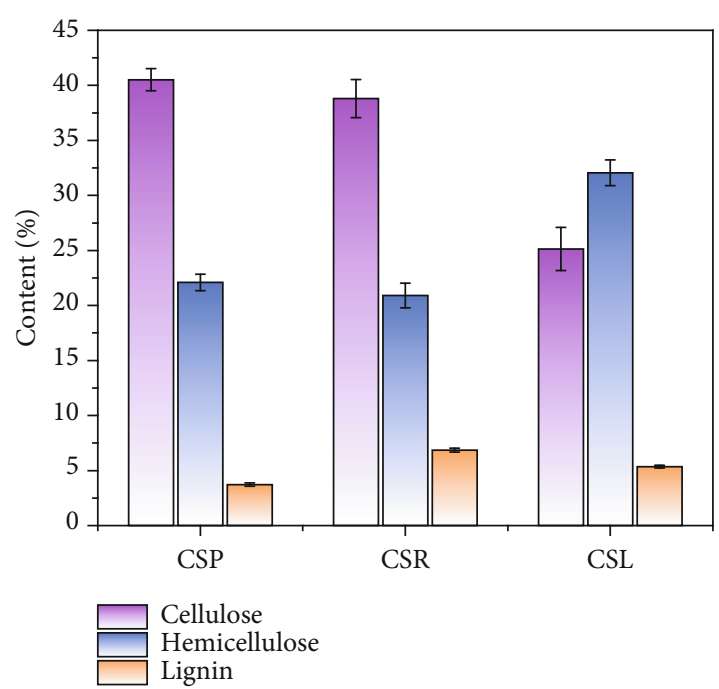

(b)

Figure 2: (a) Extraction and preparation of corn stover biomass; (b) content of different parts of corn stover.

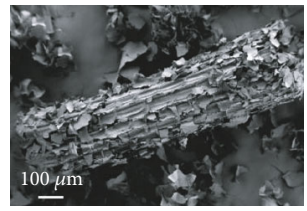

(a)

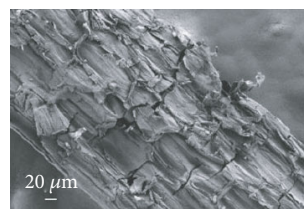

(d)

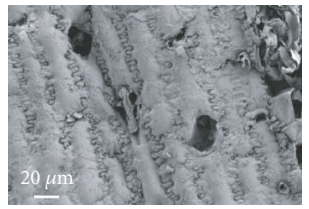

(g)

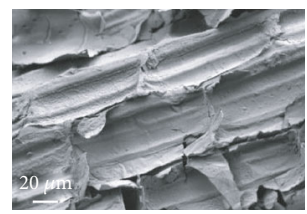

(b)

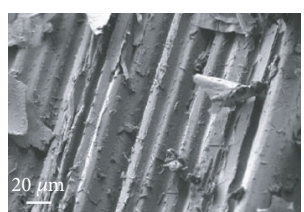

(e)

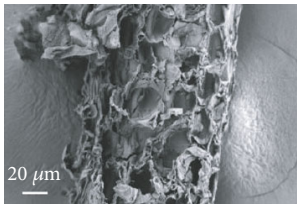

(h)

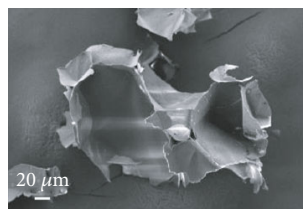

(c)

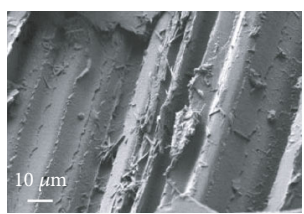

(f)

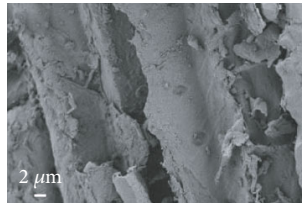

(i)

FIGURE 3: SEM photographs of corn stover pith $(a-c)$, rind $(d-f)$, and leaf (g-i) at different magnifications.

of longitudinal fibres, and the state of the CSP is relatively loose and has a certain elasticity [41]. The weight proportions of the parts in corn stover are also different, and CSR and CSP account for $60 \%$ and $20 \%$ of the total weight, respectively.

Corn stover is mainly composed of cellulose, hemicellulose, and lignin [42], and the lignocellulose compositions of various parts of CS are shown in Figure 2(b). Because of the different saccharification rates in different parts of the plant during the growth process, the content of cellulose and hemicellulose in different parts is different. Cellulose was the main component in the biomass of the straw. The lignocellulosic compositions of CSP and CSR were similar; the cellulose content in CSP reached $40.5 \%$, and that in CSR was nearly $40 \%$,
TABLE 2: The porosity characteristics of corn stover pith, rind, and leaf.

\begin{tabular}{lccc}
\hline Parameters & CSP & CSR & CSL \\
\hline Specific surface area $\left(\mathrm{m}^{2} \mathrm{~g}^{-1}\right)$ & 3.7999 & 1.2495 & 1.3717 \\
Total pore volume $\left(\mathrm{cm}^{2} \mathrm{~g}^{-1}\right)$ & 0.003829 & 0.000684 & 0.004117 \\
Average pore size $(\mathrm{nm})$ & 4.03108 & 2.1906 & 12.0042 \\
\hline
\end{tabular}

which was significantly higher than that in CSL. The hemicellulose content of CSP and CSR is similar, but the hemicellulose content of CSL was much higher than those of CSP and CSR, reaching $38.8 \%$. Lignin provides mechanical strength to the cell walls, which plays an important role in increasing the compressive strength of the stem and strengthening the cell 


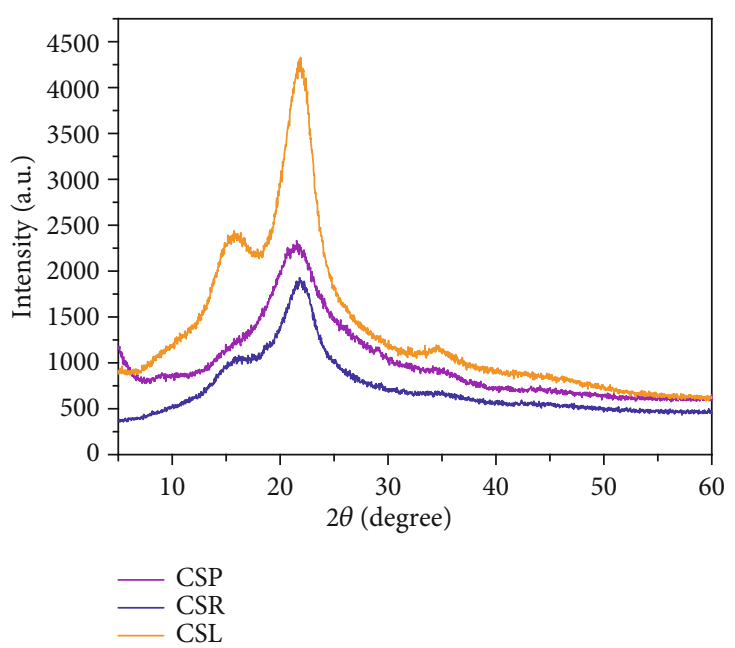

(a)

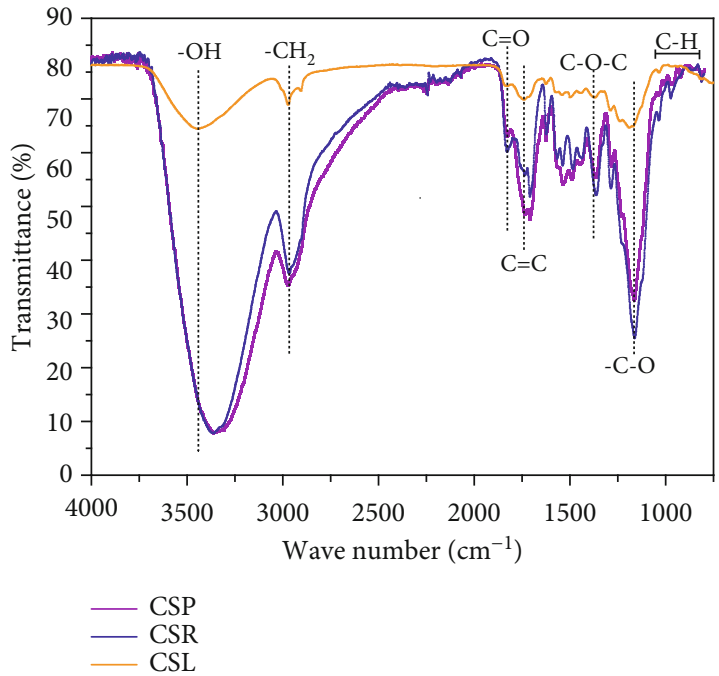

(b)

FIGURE 4: XRD (a) and FTIR (b) spectra of corn stover pith, rind, and leaf.

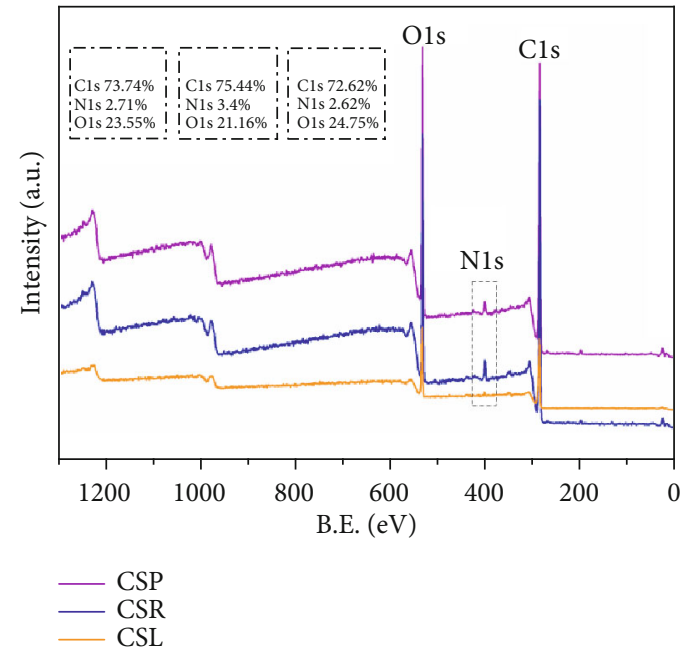

(a)
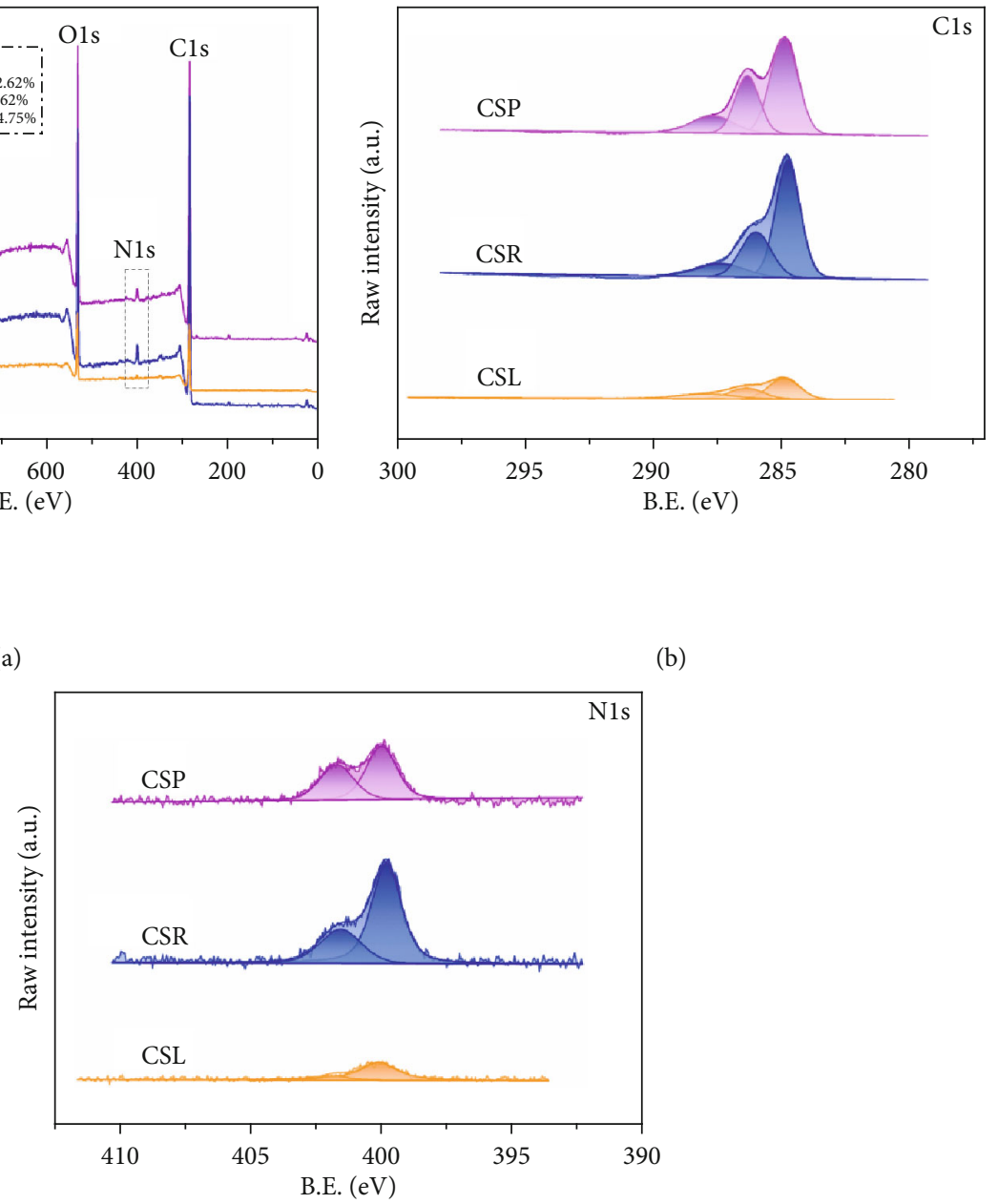

(c)

FIgURE 5: The XPS spectra of three parts of the corn stover. 
TABLE 3: Identification and quantification of C-groups and N-groups on the surfaces of the three samples.

\begin{tabular}{|c|c|c|c|c|c|c|c|}
\hline & \multirow{2}{*}{ Materials } & \multicolumn{2}{|c|}{ CSP } & \multicolumn{2}{|c|}{ CSR } & \multicolumn{2}{|c|}{ CSL } \\
\hline & & $\mathrm{BE}^{\mathrm{a}}$ & $\mathrm{AF}^{\mathrm{b}}$ & $\mathrm{BE}^{\mathrm{a}}$ & $\mathrm{AF}^{\mathrm{b}}$ & $\mathrm{BE}^{\mathrm{a}}$ & $\mathrm{AF}^{\mathrm{b}}$ \\
\hline \multirow{3}{*}{ C-groups } & $\mathrm{C}-\mathrm{C} / \mathrm{C}-\mathrm{H}$ & 284.9 & 55.1 & 284.7 & 59.5 & 284.9 & 49.5 \\
\hline & $\mathrm{C}-\mathrm{N} / \mathrm{C}-\mathrm{OH} / \mathrm{C}-\mathrm{O}-\mathrm{C}$ & 286.3 & 29.5 & 286.0 & 27.7 & 286.4 & 22.1 \\
\hline & $\mathrm{C}=\mathrm{O} / \mathrm{O}-\mathrm{C}-\mathrm{O}$ & 287.7 & 15.4 & 287.4 & 12.8 & 288.0 & 28.4 \\
\hline \multirow{2}{*}{ N-groups } & $-\mathrm{N}(\mathrm{CH})_{2} /-\mathrm{NH}_{2}$ & 400.0 & 58.4 & 399.8 & 70.7 & 400.1 & 86.1 \\
\hline & $-\mathrm{N}\left(\mathrm{CH}_{3}\right)_{3}^{+} /-\mathrm{NH}_{3}{ }^{+}$ & 401.7 & 41.6 & 401.6 & 29.3 & 401.8 & 13.9 \\
\hline
\end{tabular}

${ }^{\mathrm{a}}$ Binding energy (eV); ${ }^{\mathrm{b}}$ Atom fraction (\%).

wall. Lignin is also beneficial for enhancing the longitudinal grooming ability of plant stems; thus, the lignin content of CSR and CSL is relatively higher than that of CSP. The minimum lignin content of CSP was $3.72 \%$, and the maximum in CSR was 6.85\%. This is consistent with previous results [43]. The cell wall of CSR has a higher degree of lignification, and the lignin content of CSL and CSP is lower. From the chemical compositions determined in these experiments, the cellulose content in CSP was the highest, the hemicellulose content in CSL was the highest, and the lignin was mainly concentrated in CSR. It can be inferred that the tightness of the fibre bundle structure and the lignin content exhibit a positive correlation. However, cellulose contains a variety of active groups, and the high content of cellulose makes it easier to apply modifications to prepare adsorption materials, so it is speculated that CSP is more suitable for chemical modification. Studying the chemical composition of a material is the first step for exploring adsorption capacity, as it allows the detection of raw material variability, processes of optimization, and establishment of quality parameters.

3.1.2. Morphological Characteristics. SEM images of the three fractions of corn stover are shown in Figure 3. The structures are divided into two parts: fibrous and scattered small particles. The bar is the internal meridian of CSP, while the block-shaped CSP is composed of slices that are similar to a honeycomb porous structure. This may be the reason for its elasticity. The outer part, CSR, displayed well-ordered and intact fibres and showed more fibre cells under the epidermis than did CSP and CSL. With different morphologies, CSL had a relatively rough surface compared with the other two parts. The coarse and disordered fibres contained in CSL could increase the pore volume and external surface area of the material [22-24].

3.1.3. BET. The specific surface areas and porosity characteristics of CSP, CSR, and CSL are summarized in Table 2. The surface areas were found to be $3.80 \mathrm{~m}^{2} \mathrm{~g}^{-1}, 1.25 \mathrm{~m}^{2} \mathrm{~g}^{-1}$, and $1.37 \mathrm{~m}^{2} \mathrm{~g}^{-1}$ for CSP, CSR, and CSL, respectively. The pores can be divided into three size classes based on the pore diameters, and these classes are macropores $(>50 \mathrm{~nm})$, mesopores $(2 \mathrm{~nm}<$ diameter $<50 \mathrm{~nm})$, and micropores $(<2 \mathrm{~nm})$. The average pore sizes of all three samples were within the mesopore range. The total pore volume and average pore size of CSR are obviously the smallest. This is consistent with the SEM images showing that the CSR structure is compact and the total pore volume is small. The total pore volume

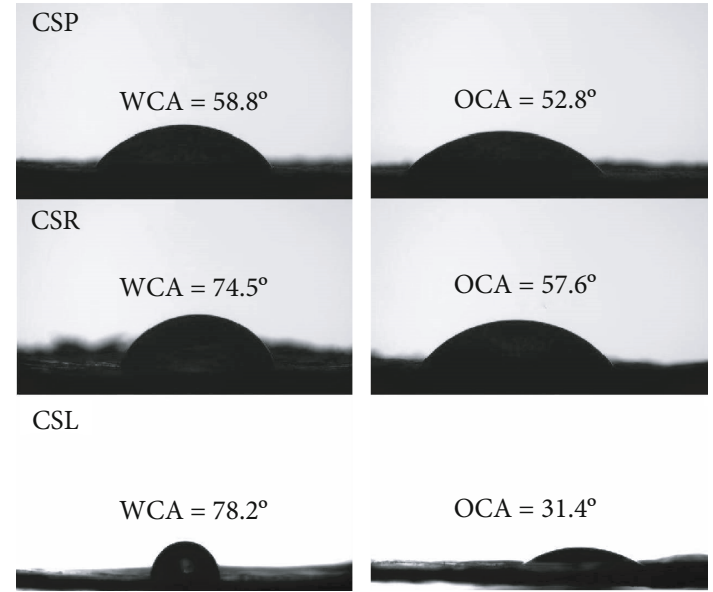

FIGURE 6: The water and oil contact angles of corn stover pith, rind, and leaf.

of the CSR is not even of the same order of magnitude as that of the CSP and CSL, and this result can affect its adsorption capacity. For CSP and CSL, much of the pore volume is unavailable to water and is still filled with air, providing buoyancy [44]. These data clearly show that the structures of each part of the corn stover are different, which can also explain the discrepancies in adsorption capacity.

3.1.4. XRD and FTIR. For the XRD patterns (Figure 4(a)), the results showed that the main peaks for CSP, CSR, and CSL were located at $21.55^{\circ}, 21.80^{\circ}$, and $21.92^{\circ}$, respectively. Similarly, both CSR and CSP revealed a minor broad peak at $2 \theta$ equivalent to $15.74^{\circ}$, but CSL shows a strong broad peak at $2 \theta$ equivalent to $16.16^{\circ}$. The crystallinity of cellulose is one of the most important characteristics contributing to its physical, chemical, and mechanical properties, and the crystallinity index (CrI) has been used to interpret the cellulose structure [45]. Calculated with formula (1), the crystallinity indices (CrIs) of the raw materials CSP, CSR, and CSL were $50.6 \%, 50.9 \%$, and $46.1 \%$, respectively. It can be seen from the calculations that the relative crystallinity of CSR is slightly higher than those of CSP and CSL.

FTIR was used to analyse the surface functional groups of all samples. The typical FTIR spectra of raw corn stover fibre over the range from 4000 to $400 \mathrm{~cm}^{-1}$ are presented in Figure 4(b). Both CSP and CSR exhibited roughly the same trends. In the high-frequency region, the band at $3323 \sim 3421 \mathrm{~cm}^{-1}$ is associated with the stretching vibration 


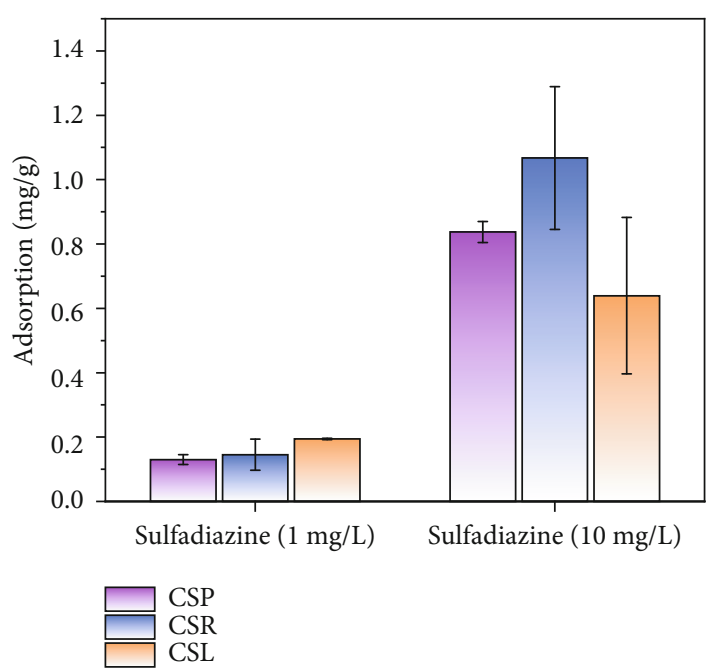

(a)

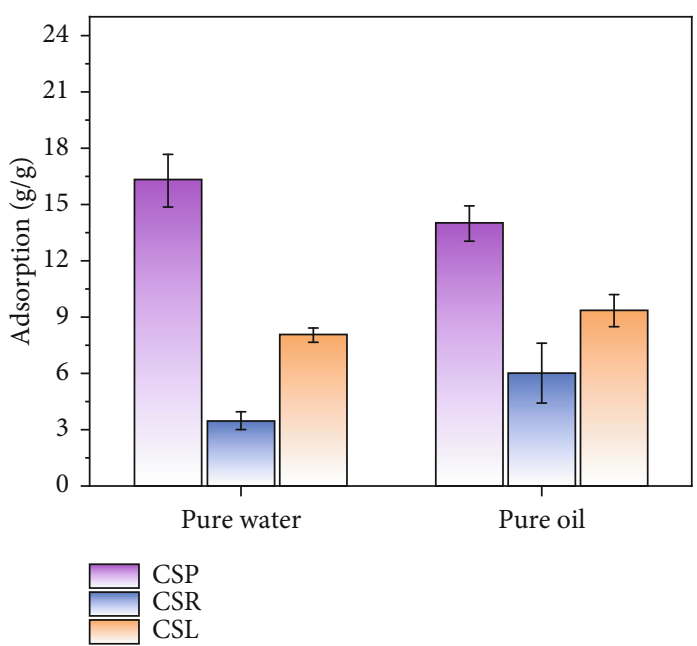

(b)

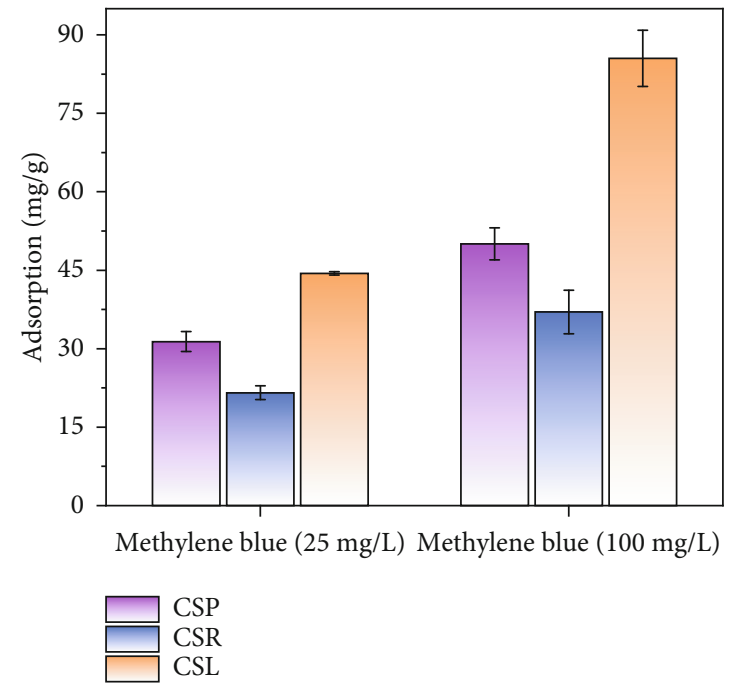

(c)

Figure 7: The adsorption capacities of different parts of the corn stover.

of the O-H bond in the molecules, characteristic of the presence of hydrophilic groups [2]. For the three tissue fractions of corn stover, the absorption peaks are attributed to the C-H bonds of alkanes, appearing from $2900 \mathrm{~cm}^{-1}$ to $2600 \mathrm{~cm}^{-1}$ [46]. This suggests the presence of $-\mathrm{CH}_{3} /-\mathrm{CH}_{2}$ groups on the corn stover surface, and these were the characteristic absorption peaks of cellulose [47]. This is consistent with the results of the composition analyses, in which the cellulose content in CSL is less than that in CSP and CSR. The absorption band at $1704 \mathrm{~cm}^{-1}$, showing high intensity in the spectra, is assigned to $\mathrm{C}=\mathrm{O}$ stretching vibrations. There are also some absorption peaks within the range $2000-1550 \mathrm{~cm}^{-1}$, which indicates the presence of lignin in corn stover [47]. The absorption band at approximately $1034 \mathrm{~cm}^{-1}$ might correspond to the stretching vibration of $\mathrm{C}-\mathrm{O}$ due to the presence of hemicellulose [22-24]. The glycosidic linkages in cellulose are indicated by the peak at $896 \mathrm{~cm}^{-1}$. Figure 4(b) illustrates that different compositions of corn stover have different peak intensities. CSP has more $\mathrm{C}=\mathrm{C}$ bonds, $\mathrm{CSR}$ has more $\mathrm{C}-\mathrm{H}$ bonds, and CSL has lower peak intensities than the other two parts, which confirms that different parts have different chemical compositions [48].

3.1.5. XPS. X-ray photoelectron spectroscopy (XPS) characterization was used to further characterize the functional groups of the samples. The surface element compositions (atomic fraction, \%) determined by XPS wide scan spectra are shown in Figure 5(a). As with the FTIR results, the compositions of CSP and CSR are approximately the same, while that of CSL differs. The high-resolution C1s and N1s spectra of the three parts of corn stover were studied to identify the differences in surface chemical binding. The $\mathrm{C} 1$ s highresolution spectra of CSP, CSR, and CSL are shown in Figure 5(b). The C1s spectra were fitted to three components, and the most intense peak at $284.9 \mathrm{eV}$ is related to $\mathrm{C}-\mathrm{C} / \mathrm{C}-\mathrm{H}$ bonds in hydrocarbons, particularly methyl bonds in straw materials. The band at approximately $286.3 \mathrm{eV}$ is usually attributed to $\mathrm{C}-\mathrm{O}$ bonds in hydroxyl $(\mathrm{C}-\mathrm{OH})$ and ether $(\mathrm{C}$ - 


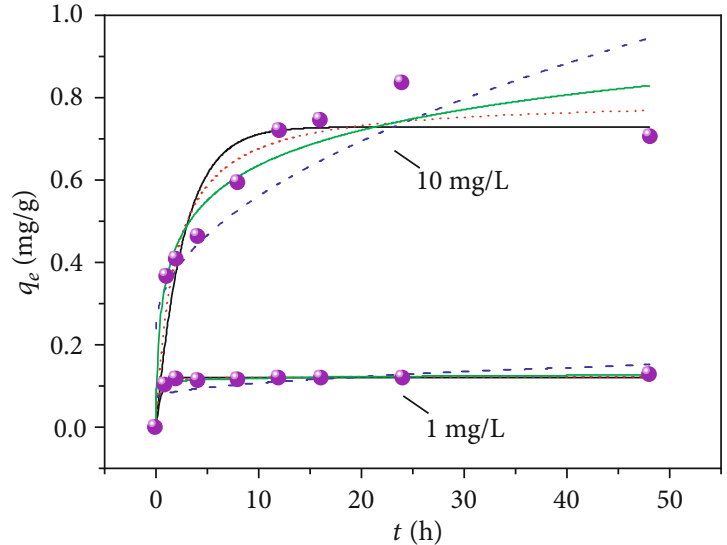

- CSP

- Pseudo-first-order model

..... Pseudo-second-order model

- - Intra-particle model

Elovich model

(a)

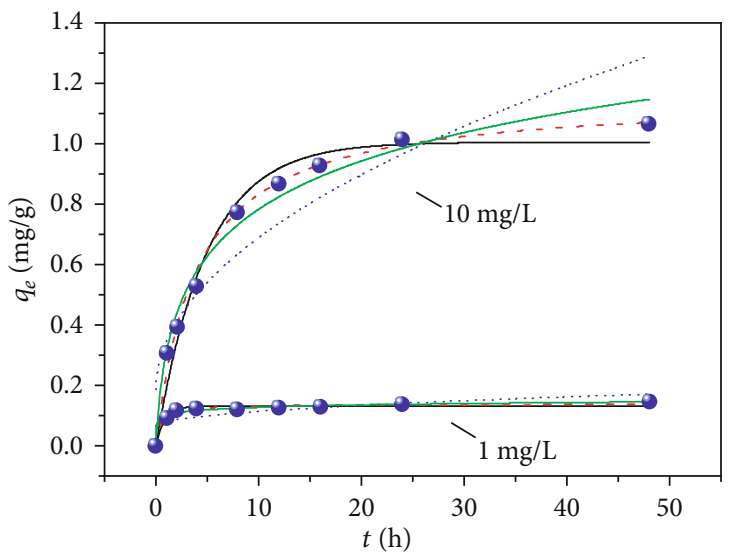

- CSR

Pseudo-first-order model

Pseudo-second-order model

- - - Intra-particle model

_ Elovich model

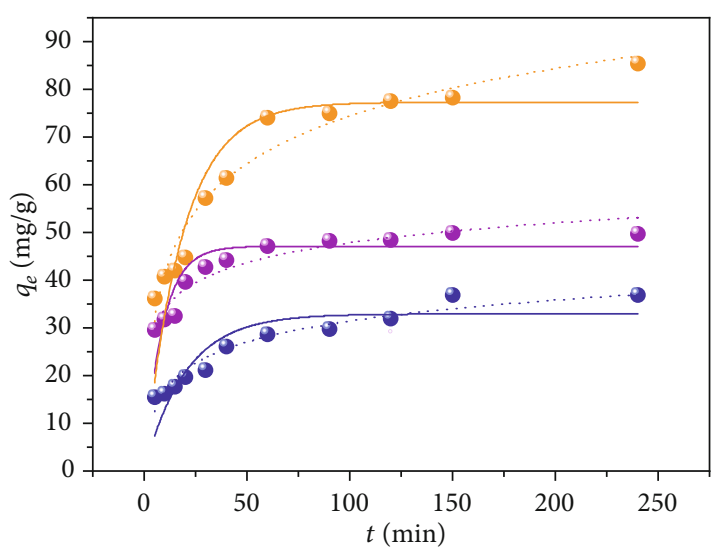

- CSP

- CSR

- CSL

- Pseudo-first-order model

...... Elovich

(b)

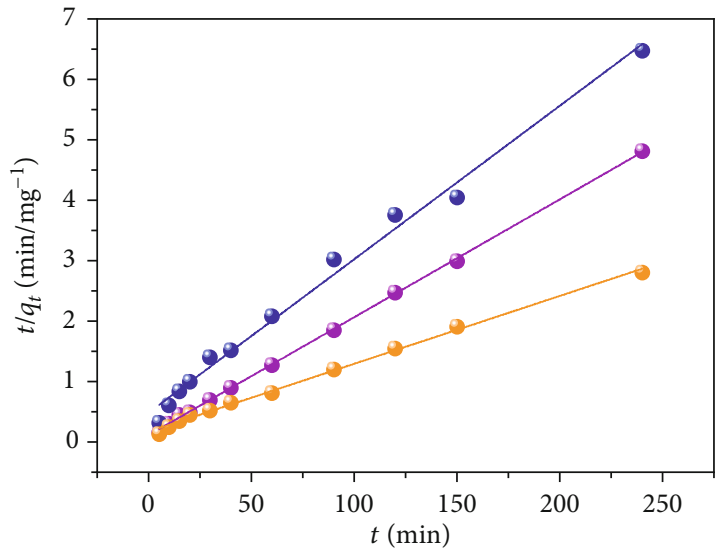

- CSP

- CSR

- CSL

— Pseudo-second-order model

(c)

(d)

Figure 8: Continued. 


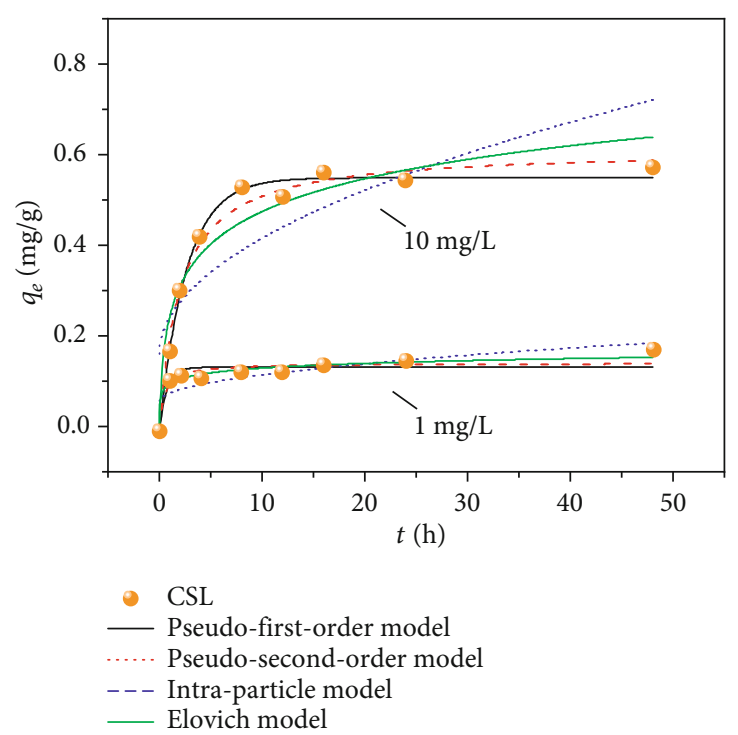

(e)

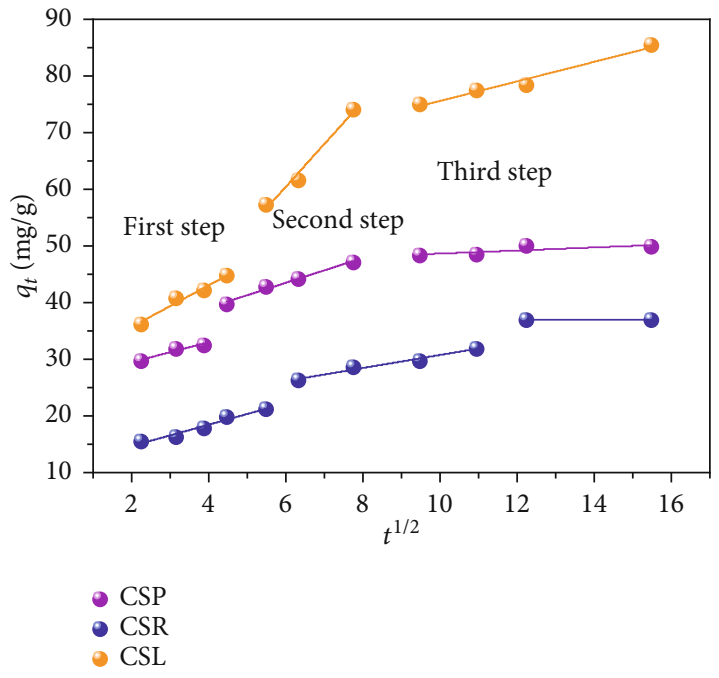

(f)

Figure 8: Adsorption kinetics of corn stover pith, rind, and leaf towards sulfadiazine (a, c, e) and methylene blue (b, d, f).

TABLE 4: Kinetic parameters for different parts of corn stover in adsorption of sulfadiazine with two solution concentrations.

\begin{tabular}{|c|c|c|c|c|c|c|}
\hline \multirow{2}{*}{$\begin{array}{l}C_{0}\left(\mathrm{mg} \mathrm{L}^{-1}\right) \\
\text { Sample }\end{array}$} & \multicolumn{3}{|c|}{1} & \multicolumn{3}{|c|}{10} \\
\hline & CSP & CSR & CSL & CSP & CSR & CSL \\
\hline$q_{e, \exp }\left(\mathrm{mg} \mathrm{g}^{-1}\right)$ & 0.13 & 0.15 & 0.19 & 0.84 & 1.07 & 0.64 \\
\hline \multicolumn{7}{|c|}{ Pseudo-first-order } \\
\hline$k_{1}\left(\mathrm{~h}^{-1}\right)$ & 2.01 & 1.19 & 1.36 & 0.37 & 0.20 & 0.38 \\
\hline$q_{e}\left(\mathrm{mgg}^{-1}\right)$ & 0.12 & 0.13 & 0.15 & 0.73 & 1.00 & 0.61 \\
\hline$R^{2}$ & 0.990 & 0.968 & 0.855 & 0.887 & 0.970 & 0.993 \\
\hline \multicolumn{7}{|c|}{ Pseudo-second-order } \\
\hline$k_{2}\left(\mathrm{~g} \mathrm{mg}^{-1} \mathrm{~h}^{-1}\right)$ & 10.16 & 5.62 & 1.94 & 1.28 & 0.23 & 0.86 \\
\hline$q_{e}\left(\mathrm{mg} \mathrm{g}^{-1}\right)$ & 0.13 & 0.15 & 0.20 & 0.75 & 1.15 & 0.66 \\
\hline$R^{2}$ & 0.999 & 0.998 & 0.988 & 0.988 & 0.999 & 0.999 \\
\hline \multicolumn{7}{|l|}{ Elovich } \\
\hline$\alpha\left(\mathrm{mg} \mathrm{g}^{-1} \mathrm{~h}^{-1}\right)$ & 1.67 & 69.96 & 15.33 & 2.11 & 0.63 & 1.13 \\
\hline$\beta\left(\mathrm{g} \mathrm{mg}^{-1}\right)$ & 203.91 & 86.66 & 60.18 & 8.09 & 4.23 & 8.63 \\
\hline$R^{2}$ & 0.995 & 0.989 & 0.962 & 0.926 & 0.982 & 0.934 \\
\hline \multicolumn{7}{|l|}{ Intraparticle } \\
\hline$k_{i}\left(\mathrm{mgg} \mathrm{g}^{-1} \mathrm{~h}^{-1 / 2}\right)$ & 0.01 & 0.02 & 0.02 & 0.02 & 0.16 & 0.09 \\
\hline$C$ & 0.07 & 0.07 & 0.07 & 0.24 & 0.18 & 0.19 \\
\hline$R^{2}$ & 0.319 & 0.491 & 0.6147 & 0.668 & 0.853 & 0.674 \\
\hline
\end{tabular}

$\mathrm{O}-\mathrm{C})$ groups. With the presence of amino groups, there is also a contribution of $\mathrm{C}-\mathrm{N}$ bonds to a peak at approximately $286.3 \mathrm{eV}$. CSL has the lowest fraction at approximately $286.3 \mathrm{eV}$, which is consistent with the results of chemical composition and FTIR analyses. The relatively weak bands ranging from 287.7 to $288.0 \mathrm{eV}$ are assigned to carbonyl groups $(\mathrm{C}=\mathrm{O})$ and $\mathrm{O}-\mathrm{C}-\mathrm{O}$ linkages of ketones and carbonyl groups in the lignocellulose structure, especially that of lignin [49]. The N1s high-resolution spectra for the three samples and their curve fitting analyses are shown in Figure 5(c).
The N1s high-resolution spectra were fitted with two components, which are assigned to free amino groups $\left(-\mathrm{N}(\mathrm{CH})_{2} /-\right.$ $\mathrm{NH}_{2}$ ) at approximately $400.0 \mathrm{eV}$ and protonated amino groups $\left(-\mathrm{N}\left(\mathrm{CH}_{3}\right)_{3}{ }^{+} /-\mathrm{NH}_{3}{ }^{+}\right)$at approximately $401.7 \mathrm{eV}$. Table 3 summarizes the atomic fractions of free and protonated groups on the surfaces of the samples. Most amino groups on the surfaces of CSP, CSR, and CSL are free amino groups, accounting for $58.4 \%, 70.7 \%$, and $86.1 \%$ of the amino groups present, respectively. The atom fractions of protonated amino groups $\left(-\mathrm{N}\left(\mathrm{CH}_{3}\right)_{3}{ }^{+} /-\mathrm{NH}_{3}{ }^{+}\right)$on the surface of 
TABLE 5: Kinetic parameters for the adsorption of methylene blue.

\begin{tabular}{|c|c|c|c|c|c|c|c|}
\hline Sample & CSP & CSR & CSL & & CSP & CSR & CSL \\
\hline$q_{e, \exp }\left(\mathrm{mg} \mathrm{g}^{-1}\right)$ & 50.03 & 37.00 & 85.48 & $q_{e, \exp }\left(\mathrm{mg} \mathrm{g}^{-1}\right)$ & 50.03 & 37.00 & 85.48 \\
\hline \multicolumn{5}{|c|}{ Pseudo-first-order model } & \multicolumn{3}{|c|}{ Intraparticle } \\
\hline$k_{1}\left(\mathrm{~h}^{-1}\right)$ & 0.02 & 0.04 & 0.01 & $k_{t 1}\left(\mathrm{mgg} \mathrm{g}^{-1} \mathrm{~h}^{-1 / 2}\right)$ & 28.39 & 25.97 & 10.89 \\
\hline$q_{e}\left(\mathrm{mgg}^{-1}\right)$ & 16.06 & 44.21 & 46.48 & $C_{1}\left(\mathrm{mg} \mathrm{g}^{-1}\right)$ & 3.67 & 1.76 & 1.89 \\
\hline$R^{2}$ & 0.9534 & 0.6658 & 0.9069 & $R^{2}$ & 0.976 & 0.9480 & 0.958 \\
\hline \multicolumn{4}{|c|}{ Pseudo-second-order model } & $k_{t 2}\left(\mathrm{mg} \mathrm{g}^{-1} \mathrm{~h}^{-1 / 2}\right)$ & 15.09 & 30.35 & 19.25 \\
\hline$k_{2}\left(\mathrm{~g} \mathrm{mg}^{-1} \mathrm{~h}^{-1}\right)$ & 0.003 & 0.001 & 0.001 & $C_{2}\left(\mathrm{mg} \mathrm{g}^{-1}\right)$ & 7.56 & 2.19 & 1.15 \\
\hline$q_{e}\left(\mathrm{mg} \mathrm{g}^{-1}\right)$ & 51.28 & 39.37 & 89.29 & $R^{2}$ & 0.982 & 0.983 & 0.968 \\
\hline$R^{2}$ & 0.9996 & 0.9911 & 0.9967 & $k_{t 3}\left(\mathrm{mg} \mathrm{g}^{-1} \mathrm{~h}^{-1 / 2}\right)$ & 58.34 & 45.95 & 36.94 \\
\hline \multicolumn{4}{|l|}{ Elovich } & $C_{3}\left(\mathrm{mg} \mathrm{g}^{-1}\right)$ & 1.73 & 0.27 & 0.01 \\
\hline$\alpha\left(\mathrm{mgg}^{-1} \mathrm{~h}^{-1}\right)$ & 19.98 & 6.04 & 0.92 & $R^{2}$ & 0.975 & 0.6444 & 1 \\
\hline$\beta\left(\mathrm{g} \mathrm{mg}^{-1}\right)$ & 6.04 & 6.35 & 14.37 & & & & \\
\hline$R^{2}$ & 0.9176 & 0.9489 & 0.9525 & & & & \\
\hline
\end{tabular}

CSP, CSR, and CSL are 41.6\%, 29.3\%, and $13.9 \%$, respectively. As protonated amino groups can effectively remove anions through electrostatic interactions, CSR and CSL, with fewer protonated amino groups, exhibit poor anionic adsorption performance [50].

3.1.6. Contact Angle Measurements. Surface hydrophobicity is one of the most important properties for adsorption because water molecules can compete with adsorbates during the sorption process. Figure 6 shows the water contact angle (WCA) results for CSP, CSR, and CSL, with values of $58.8^{\circ}$, $74.5^{\circ}$, and $78.2^{\circ}$, respectively, and the oil contact angles (OCAs) of $52.8^{\circ}, 57.6^{\circ}$, and $31.4^{\circ}$, respectively, which show that CSP, CSR, and CSL are all amphiphilic (with WCA and OCA below $90^{\circ}$ ). The WCAs of CSR and CSL are obviously larger than that of CSP. The poor hydrophobicity of pith is due to the flat surface and the greater proportion of cellulose, which is hydrophilic and has abundant hydrophilic hydroxyl groups that promote the wetting with water. The OCA of CSP and CSR are similar. CSL is the most lipophilic, which may be related to the lower content of cellulose and the low surface energy. It can also be seen from the FTIR results that the structure of CSL has fewer hydrophilic hydroxyl groups, so its hydrophobicity and lipophilicity are greater than those of CSP and CSR.

3.2. Adsorption Capacity. As shown in Figure 7, the adsorption trends of different parts of CS for antibiotics, oils, and dyes are significantly different. Experimental tests showed that there was little difference between CSR and CSP for the adsorption of low-concentration antibiotics $\left(1 \mathrm{mg} \mathrm{L}^{-1}\right)$, but CSL showed a better adsorption capacity. For the adsorption of high-concentration antibiotics $\left(10 \mathrm{mg} \mathrm{L}^{-1}\right)$, the adsorption capacity of CSR can reach $1.067 \mathrm{mg} \mathrm{g}^{-1}$, which is 1.67 times higher than that of CSL. The three fractions showed similar adsorption capacities for pure water and oil. CSP and CSL can effectively adsorb oil and water, possibly because they have relatively high surface areas and pore volumes, with which to store more oil and water molecules. They have more pores, and the buoyancy obtained makes it easier to absorb surface oil slicks. However, the total pore volume of CSR is only $0.000684 \mathrm{~cm}^{2} \mathrm{~g}^{-1}$, which makes it difficult to absorb viscous liquids such as water. CSL has obvious advantages over the other fractions in adsorbing methylene blue. For the $100 \mathrm{mg} \mathrm{L}^{-1}$ methylene blue solution, the adsorption capacity of CSL reached $85.48 \mathrm{mgg}^{-1}$, which was 1.71 times that of CSP and 2.31 times that of CSR. The reason is related to their unique surface characteristics, and based on XPS analysis, CSL, with fewer protonated amino groups, may have better cationic adsorption performance.

3.3. Adsorption Kinetics. The plots of adsorption capacity versus time with different initial sulfadiazine concentrations and comparisons of adsorption of sulfadiazine by different parts of corn stover are shown in Figure 8. SD with a low concentration of $1 \mathrm{mg} \mathrm{L}^{-1}$ was quickly adsorbed within the first $2 \mathrm{~h}$, which may be due to the occurrence of adsorption on the outer surface, and then, the adsorption equilibrium was reached at $4 \mathrm{~h}$. The lower the pollutant concentration was, the higher the adsorption rate was. This result may occur due to the effective active sites enriched on the adsorbent surface during the initial process, which may contribute to the overall adsorption kinetics. There are usually three steps in the adsorption process: (1) the instantaneous adsorption stage, (2) the slow adsorption stage, and (3) the equilibrium stage [51]. Over time (i.e., in the slow adsorption stage), the decrease in adsorption capacity may be mainly caused by the gradual blockage of micropores and mesopores in the material, the gradual occupation of available adsorption sites, and the slow diffusion of pollutants into the pores of the material. For the $10 \mathrm{mg} \mathrm{L}^{-1} \mathrm{SD}$ solution, fast adsorption by CSP and CSR occurred within $0-4 \mathrm{~h}, 4-24 \mathrm{~h}$ corresponded to the slow adsorption stage, and equilibrium was reached in $24 \mathrm{~h}$. The adsorption by CSL was the fastest, and adsorption equilibrium could be reached within $16 \mathrm{~h}$. 

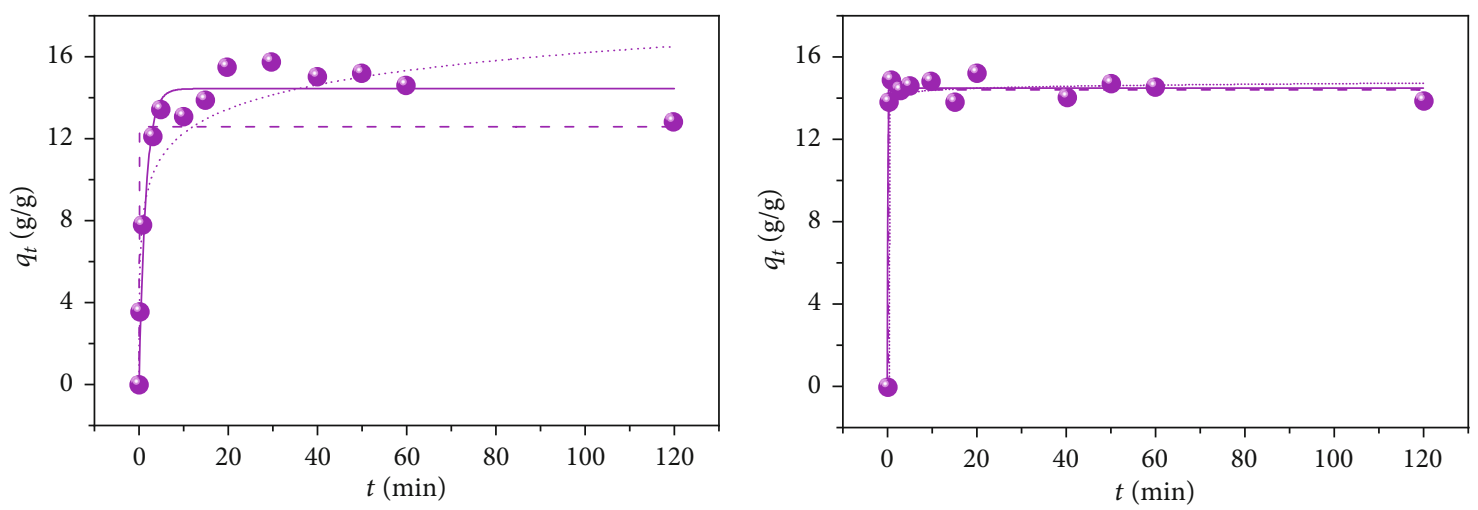

- CSP

Pseudo-first-order model

- - - Pseudo-second-order model

..... Elovich model

(a)

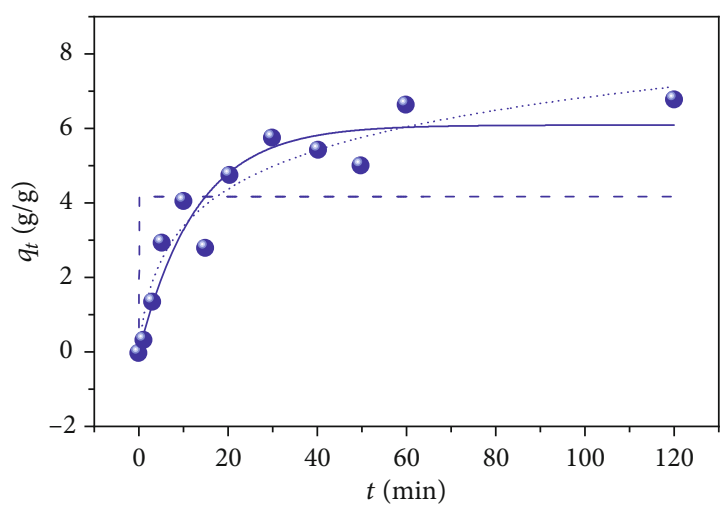

- CSP

Pseudo-first-order model

- - - Pseudo-second-order model

..... Elovich model

(b)

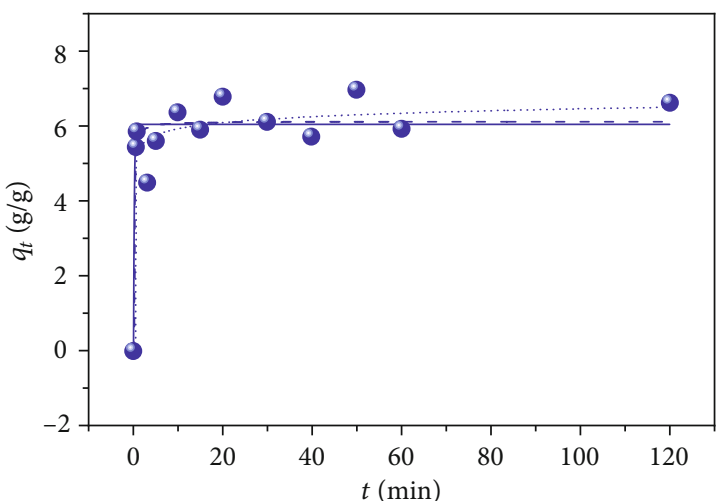

- CSR

— Pseudo-first-order model

- - - Pseudo-second-order model

..... Elovich model

- CSR

- Pseudo-first-order model

- - - Pseudo-second-order model

.... Elovich model

(c)

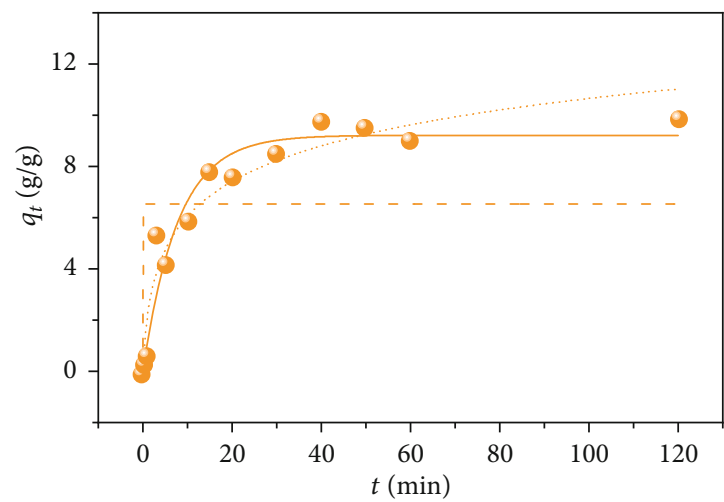

(d)

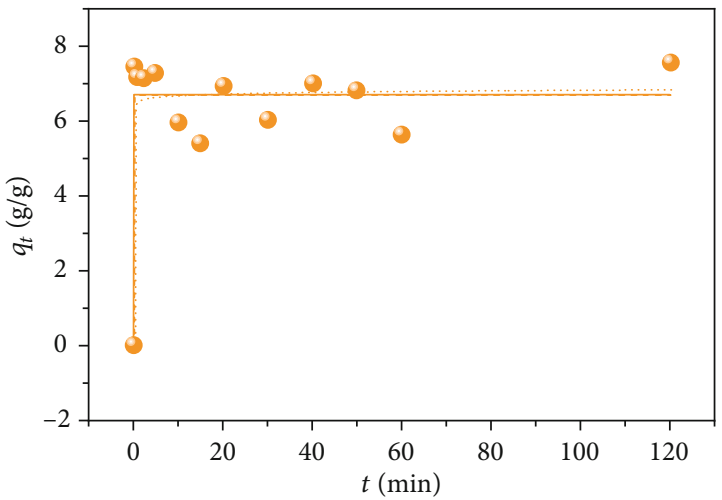

- CSL

Pseudo-first-order model

Pseudo-second-order model

Elovich model

- CSL

Pseudo-first-order model

- - - Pseudo-second-order model Elovich model

(e)

(f)

Figure 9: Adsorption kinetics for corn stover pith, rind, and leaf with oil-water solutions at low initial concentrations (a, c, e) and high initial concentrations (b, $d, f)$. 
TABLE 6: Kinetic parameters for adsorption of two concentrations of the oil-water solution.

\begin{tabular}{|c|c|c|c|c|c|c|c|c|c|c|c|}
\hline \multirow{2}{*}{\multicolumn{2}{|c|}{$\begin{array}{c}\text { Kinetic } \\
\text { parameters }\end{array}$}} & \multicolumn{4}{|c|}{ Pseudo-first-order } & \multicolumn{3}{|c|}{ Pseudo-second-order } & \multicolumn{3}{|c|}{$\begin{array}{l}\text { Elovich } \\
\end{array}$} \\
\hline & & $q_{e, \exp }\left(\mathrm{gg}^{-1}\right)$ & $k_{1}\left(\min ^{-1}\right)$ & $q_{e}\left(\mathrm{gg}^{-1}\right)$ & $R^{2}$ & $k_{2}$ & $q_{e}\left(\mathrm{gg}^{-1}\right)$ & $R^{2}$ & $\alpha\left(\mathrm{gg}^{-1} \min ^{-1}\right)$ & $\beta\left(\mathrm{gg}^{-1}\right)$ & $R^{2}$ \\
\hline \multirow{3}{*}{$10 \mathrm{~g} \mathrm{~L}^{-1}$} & CSP & 14.83 & 0.69 & 14.23 & 0.970 & 0.08 & 13.34 & 0.991 & 224.62 & 0.59 & 0.833 \\
\hline & CSR & 6.74 & 0.10 & 5.82 & 0.900 & 0.14 & 7.13 & 0.962 & 1.18 & 0.44 & 0.919 \\
\hline & CSL & 10.70 & 0.12 & 9.70 & 0.944 & 0.09 & 10.91 & 0.976 & 3.74 & 0.49 & 0.939 \\
\hline \multirow{3}{*}{$67 \mathrm{gL}^{-1}$} & CSP & 14.25 & 6.34 & 14.48 & 0.989 & 0.07 & 14.04 & 0.999 & 1.72 & 7.31 & 0.983 \\
\hline & CSR & 6.52 & 4.66 & 6.04 & 0.869 & 0.15 & 6.56 & 0.994 & 4.55 & 4.38 & 0.907 \\
\hline & CSL & 7.13 & 83.63 & 6.71 & 0.865 & 0.14 & 7.20 & 0.976 & 9.99 & 15.90 & 0.849 \\
\hline
\end{tabular}

The kinetic data of two initial sulfadiazine concentrations were fitted to typical kinetic models, which are listed in Table 1, and the parameters obtained from these model fittings are given in Table 4 . By comparing the $R^{2}$ values for fits to the pseudo-first-order equations and pseudo-secondorder equations, it is obvious that the $R^{2}$ values of the pseudo-second-order model (0.988-0.999) are closer to 1 . The correlation coefficients are between 0.926 and 0.995 for the Elovich kinetic model. Intraparticle diffusion mostly occurs in the slow adsorption process. In most cases, the intraparticle diffusion model is not applicable to the entire contact time range. Lower correlation coefficients obtained for the intraparticle model showed that there is no prominent relationship between that model and the experimental kinetic data. From the fitting results, it is seen that the adsorption of sulfadiazine by the three structural components of corn stover more closely follows the pseudo-second-order kinetic model, which indicates that chemical adsorption may be the rate-limiting step that controls the adsorption of antibiotics by stover. This can also explain why, although CSR has the smallest pore volume, it has outstanding advantages in the adsorption of SD.

Figures 8(b), 8(d), and 8(f) show four MB adsorption kinetics on different parts of the corn stover. The concentration of methylene blue solution in the kinetic adsorption experiment was $100 \mathrm{mg} \mathrm{L}^{-1}$. The values of the constants for the kinetic models are shown in Table 5. The data showed good agreement with the pseudo-second-order kinetic models $\left(R^{2}>0.9911\right)$. In addition, the $q$ values $\left(q_{e}\right.$, cal $)$ determined from the pseudo-second-order model were closer to the experimental $q$ values $\left(q_{e}\right.$, exp $)$, suggesting that the pseudo-second-order model fits the MB adsorption data well. Adsorbate transport from the solution phase to the surface of the adsorbent particles occurs in several steps. The overall adsorption process may be controlled by one or more steps, e.g., film or external diffusion, pore diffusion, surface diffusion and adsorption on the pore surface, or a combination of steps [52]. Figure 8(f) presents the plots of $q_{t}$ versus $t^{1 / 2}$ for methylene blue adsorption, and the parameters for the intraparticle model are listed in Table 5. The $k_{t i}$ and $C$ values were calculated from the slope and intercept, respectively. It can be seen that there are mainly three linear regions. Some researchers have proposed that, assuming that the adsorption process is affected by three steps, the first straight part is described as macroscopic prediffusion and must pass through the origin (representing the external mass transfer zone or surface adsorption), the second part is the gradual adsorption stage, and the third regression line tends towards adsorption equilibrium. Among these steps, intraparticle diffusion is dominant [53]. The calculated parameters show good fits at each stage, which prove that the adsorption of $\mathrm{MB}$ is affected by diffusion within the particles, but this is not the only rate-limiting step.

The plots of $q_{t}$ versus $t$ at different initial oil concentrations ( $1.5 \mathrm{~g}$ oil in $150 \mathrm{~mL}$ water or $10 \mathrm{~g}$ oil in $150 \mathrm{~mL}$ water) are shown in Figure 9. To determine the adsorption mechanism, three kinetic models were tested to fit the experimental data obtained for oil-water adsorption in batch experiments. For the pseudo-first-order model, the values of $k_{1}$ and $q_{e}$ are fitted by $q_{e}$ and $t$ correlation experimental data. A plot of $t / q_{t}$ vs. $t$ gives a linear relationship for the sorption of the oilwater mixture onto corn stover. The values of $k_{2}$ and $q_{e}$ were determined from the slope and intercept of this plot and are listed in Table 6. After comparison, the correlation coefficients $\left(R^{2}\right)$ are superior for the pseudo-second-order model. The pseudo-first-order kinetic equations are usually only applicable for describing the initial stage of adsorption. The mechanism is a physical adsorption process, while the pseudo-second-order model can better describe the whole process of adsorption.

3.4. Adsorption Isotherms. In batch sorption, the initial concentration of the target pollutant in the solution plays a key role as a driving force to overcome the mass transfer resistance between the aqueous and solid phases. Therefore, the amount of target pollutant adsorbed was expected to be higher with a higher initial concentration. Langmuir and Freundlich isotherm models are used to describe the adsorption of pollutants on biomass in the equilibrium phase. The capacity of the adsorbent can be predicted by plotting the adsorption data with the equilibrium isotherm model. Figures 10(a)-10(c) show that the adsorption trends in CSP, CSR, and CSL increase with the initial concentration of sulfadiazine in the range of $0.5-20 \mathrm{mg} \mathrm{L}^{-1}$. The parameters of the Langmuir and Freundlich models are shown in Table 7. For sulfadiazine, it is suggested that the maximum sorption capacities of the three different parts of corn stover followed the trend CSR > CSP > CSL. There is no significant correlation between the amount of SD adsorption and the total pore volumes or average pore sizes of the different samples. For CSP and CSL, the $R^{2}$ values for the Langmuir model were larger than those of the Freundlich model, suggesting 


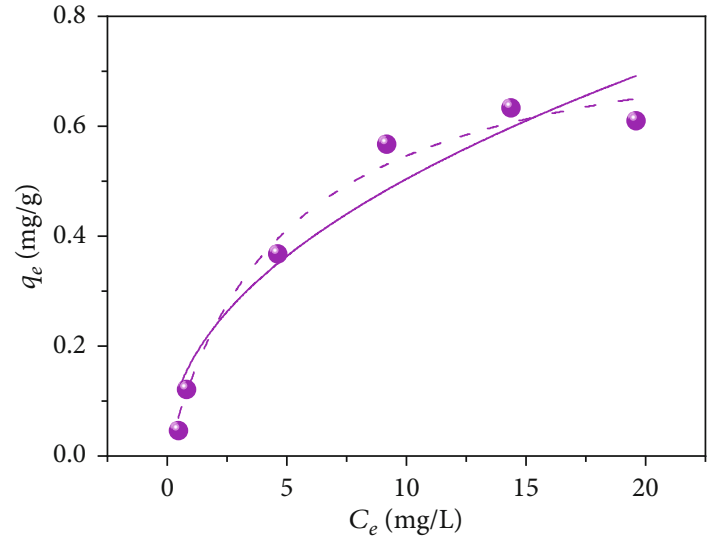

- CSP

- Langmuir

- - Freundlich

(a)

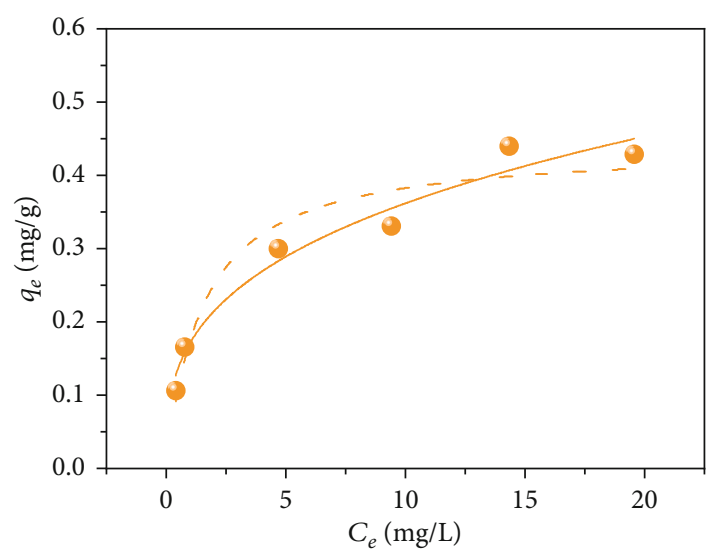

- CSL

Langmuir

Freundlich

(c)

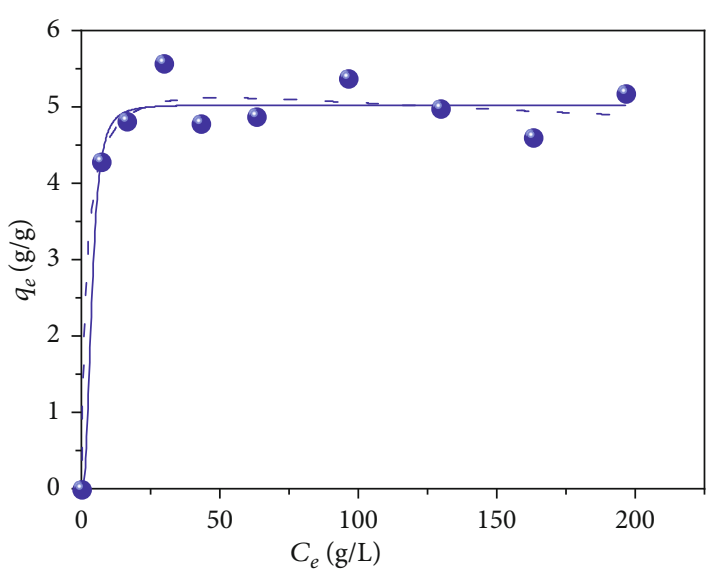

- CSL

Langmuir Freundlich

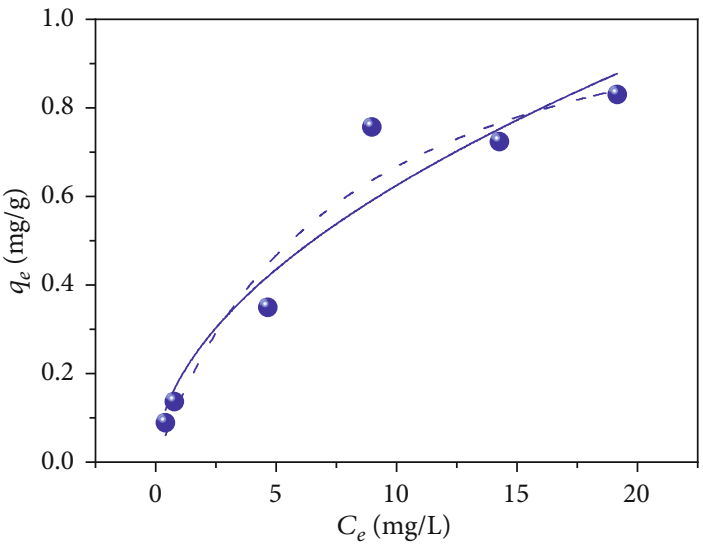

- CSR

Langmuir

- - - Freundlich

(b)

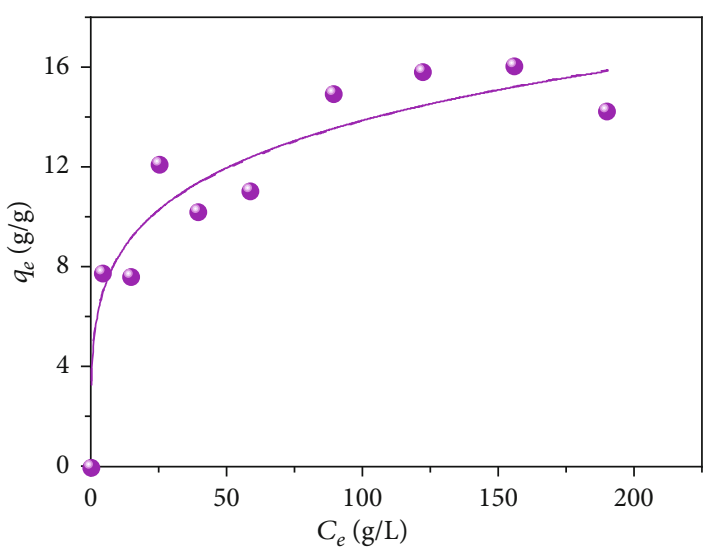

- CSP

Langmuir

-- Freundlich

(d)

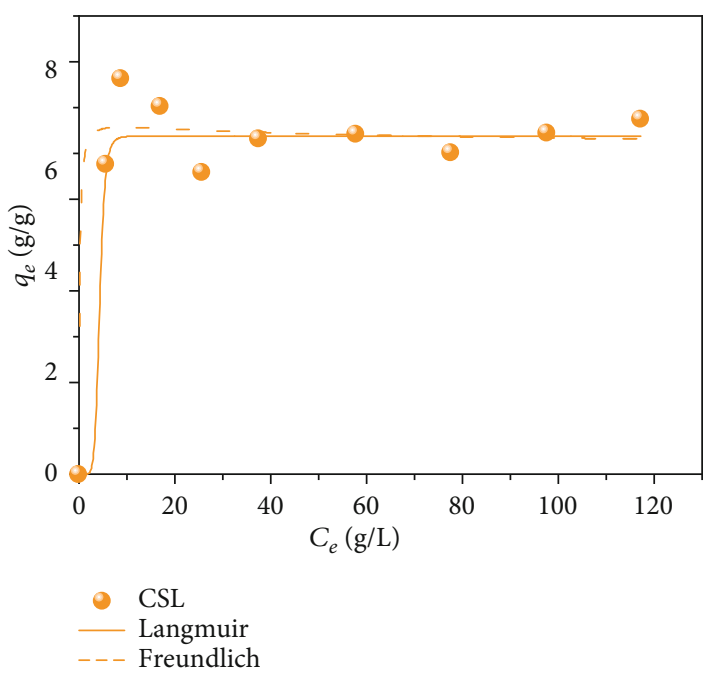

(e)

Figure 10: Continued. 


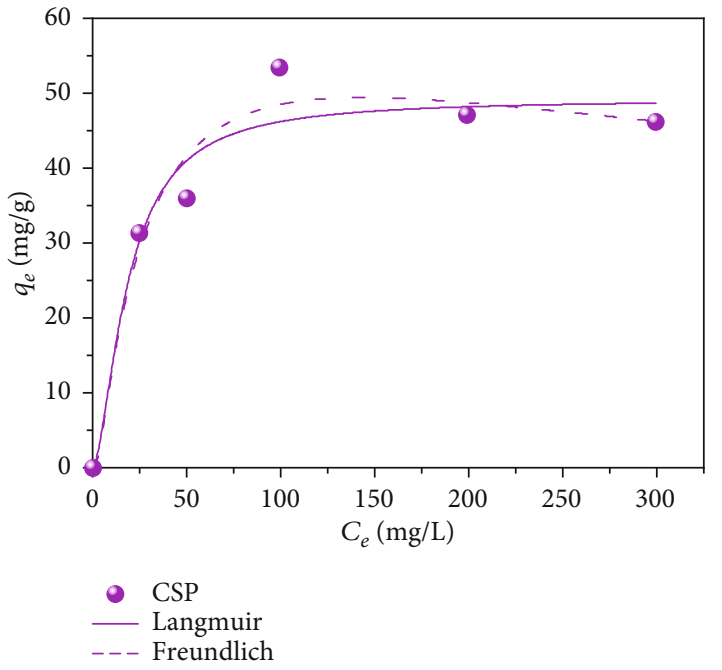

(g)

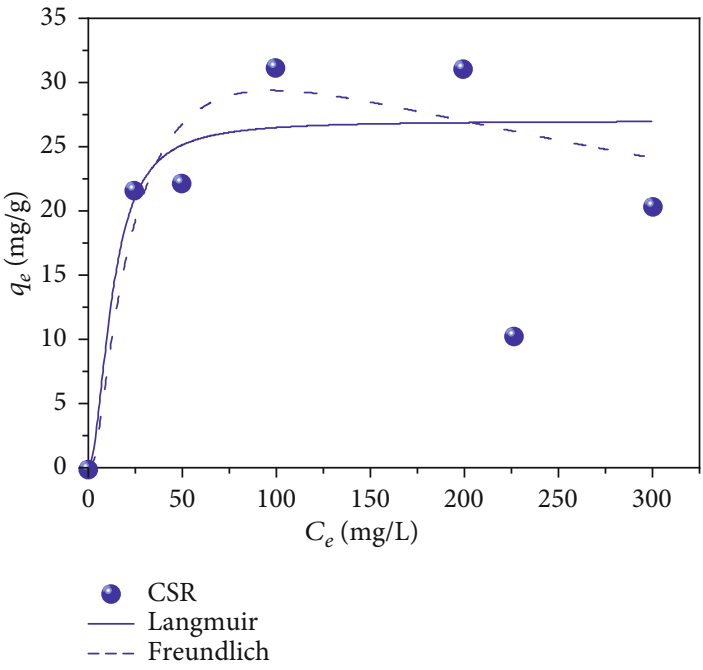

(h)

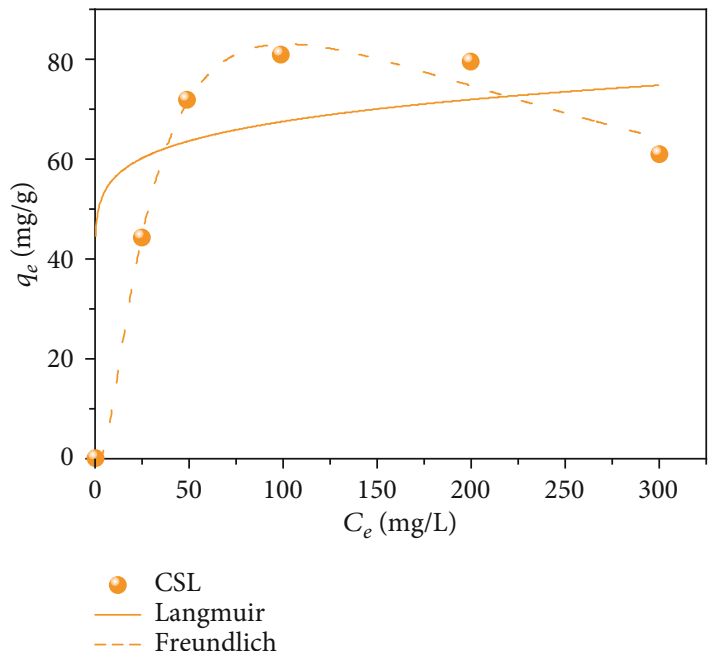

(i)

FIGURE 10: Sorption isotherms for sulfadiazine $(\mathrm{a}-\mathrm{c})$, the oil-water solution $(\mathrm{d}-\mathrm{f})$, and methylene blue (g-i) with different parts of the corn stover.

that the Langmuir model fit the equilibrium data better. The Langmuir isotherm model assumes monolayer sorption with a homogenous distribution of adsorption sites and sorption energies but no interactions between the adsorbed molecules or ions. Hence, monolayer physical adsorption played a dominant role in sulfadiazine adsorption by CSP and CSL. However, the results for adsorption of sulfadiazine on CSR are different, and the Freundlich model fits better. The Freundlich isotherm is an equation used to describe the adsorption that takes place on a heterogeneous surface with interactions between the adsorbed ions. The value of $n$ obtained from the Freundlich isotherm for the adsorption of sulfadiazine on corn stover was found to vary from 0 to 10 , which confirmed that the adsorption is favorable.

For the oil-water solution and methylene blue adsorptions, the equilibrium data were usually fitted by Langmuir and Freundlich models (Figure 10). The $R^{2}$ and isotherm constants for these models for the sorption of oil or methylene blue onto corn stover are shown in Table 7. For oil, the adsorption capacity of CSP can reach $16.867 \mathrm{gg}^{-1}$, which is more than twice that of CSR and CSL. Although the regression coefficient $(>0.97)$ obtained by fitting the Langmuir model is significantly larger than that obtained by fitting the Freundlich model, some scholars have proposed that the thickness of the formed oil layer and the use of a large amount of oil adsorption with the isotherm model may be biased. In the case of a high concentration of oil, the oil quickly forms thick oil layers on the adsorbent surfaces. Therefore, the adsorbent surface no longer plays the chemical role of adsorbing more oil [44].

It is obvious that CSL has the best adsorption capacity for methylene blue, exceeding $80 \mathrm{mgg}^{-1} . K_{f}$ is the Freundlich isotherm constant related to the adsorption capacity. The $K_{f}$ value of CSL is significantly higher than that of CSP and CSR, which also confirms its strongest adsorption capacity. Unlike the case of adsorption of antibiotics, CSR exhibits the smallest adsorption capacity. The observed $R^{2}$ in Table 7 shows that the correlation coefficient values for the 
TABLE 7: Isotherm constants for adsorption of sulfadiazine, oil-water, and methylene blue onto different adsorbents.

\begin{tabular}{|c|c|c|c|c|c|c|c|c|}
\hline & \multicolumn{4}{|c|}{ Langmuir } & \multicolumn{3}{|c|}{ Freundlich } \\
\hline & & $Q_{m}, \exp$ & $K_{L}\left(\mathrm{~L} \mathrm{mg}^{-1}\right)$ & $q_{e}\left(\mathrm{mg} \mathrm{g}^{-1}\right)$ & $R^{2}$ & $K_{F}\left(\mathrm{mg} / \mathrm{L}^{(1-1 / n)} \mathrm{g}\right)$ & $n$ & $R^{2}$ \\
\hline \multirow{3}{*}{ Sulfadiazine } & CSP & 0.64 & 0.18 & 0.83 & 0.968 & 0.11 & 1.50 & 0.948 \\
\hline & CSR & 0.83 & 0.17 & 1.06 & 0.932 & 0.16 & 1.67 & 0.979 \\
\hline & CSL & 0.44 & 0.51 & 0.47 & 0.98 & 0.16 & 2.89 & 0.973 \\
\hline \multirow{3}{*}{ Oil-water } & CSP & 16.87 & 0.06 & 17.18 & 0.976 & 5.47 & 4.18 & 0.925 \\
\hline & CSR & 5.55 & 0.20 & 4.97 & 0.991 & 4.47 & 37.18 & 0.917 \\
\hline & CSL & 7.32 & 0.15 & 7.31 & 0.975 & 5.51 & 31.15 & 0.880 \\
\hline \multirow{3}{*}{ Methylene blue } & CSP & 53.41 & 0.130 & 48.31 & 0.991 & 19.49 & 5.91 & 0.927 \\
\hline & CSR & 31.36 & -0.065 & 21.55 & 0.932 & 19.61 & 19.19 & 0.964 \\
\hline & CSL & 80.64 & -0.134 & 64.10 & 0.863 & 36.32 & 7.61 & 0.908 \\
\hline
\end{tabular}

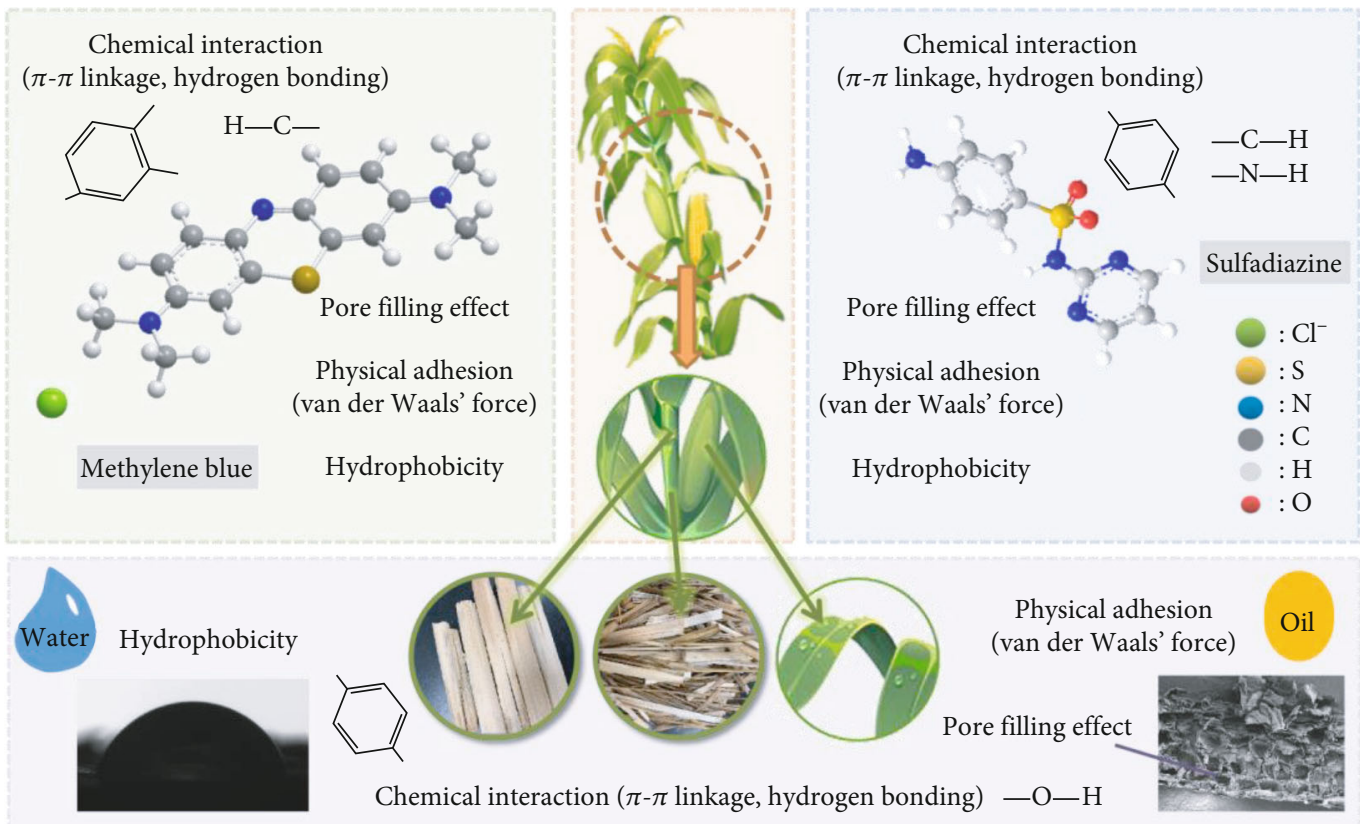

FIgURE 11: The adsorption mechanisms of corn stover toward multipollutant.

Langmuir isotherm are comparatively higher than those for the Freundlich analysis in the range of 0.932-0.991. The results show that the Langmuir model is consistent with the experimental data for different parts of the corn stalk, which means that methylene blue on the sample surface exists as a single layer.

3.5. Adsorption Mechanisms. Contaminants can be sorbed to adsorbents by four possible effects: (i) physical adhesion (van der Waals' force), (ii) pore filling effect, (iii) chemical interaction, and (vi) hydrophobicity [54]. Hence, the sorption performance is significantly related to structural characters and functional groups of adsorbents [55]. Based on the structural analysis by BET, XRD, FTIR, SEM, and contact angle measurements, and fitting results of the adsorption models, the possible adsorption mechanisms are elucidated in Figure 11.

Research indicates that the adsorbents with a large surface area and high porosity exhibit favorable adsorption towards dyes and oils [56]. As shown in Table 2, CSP and CSL had an excellent porous structure, which can increase in more adsorption sites. It is also pointed out that hydrophobicity plays a vital role in the interaction between the adsorbate and the adsorbent and is especially associated with oil sorption [57]. Both surfaces of CSP and CSL have good amphipathic (Figure 6), which could easily attract oil and MB. A large number of $\mathrm{OH}$ groups (Figure 4(b)) exist on the surface of lignocellulose adsorbents, which can easily form hydrogen bonding between adsorbents and adsorbates. Based on the above analysis, the pore filling effect, hydrogen bonding, van der Waals' force, and surface hydrophobicity were considered to be combined actions in the adsorption process of oil and MB. For SD adsorption, although CSR has the lowest specific surface area and pore volume, its sorption capacity was the highest, which was primarily owed to the $\pi-\pi$ interaction. The $\mathrm{C}-\mathrm{C} / \mathrm{C}=\mathrm{C}$ proportion of $\mathrm{CSR}$ was greater than CSP and CSL (Table 3), which could provide a strong $\pi-\pi$ linkage force for SD sorption [58]. 


\section{Conclusions}

The functioned agriculture wastes are able to effectively adsorb a variety of environmental pollutants. However, their performance can be influenced by many factors such as raw materials resource and raw material composition, requiring an understanding of the raw materials to be utilized effectively. This study highlighted the potential of corn stover fractions (CSP, CSR, and CSL) for the sorption of organic pollutants. The lignocellulose structural compositions of CSP and CSR are similar, and CSL has a higher hemicellulose content. The structure of CSP is fluffy, and CSR and CSL have higher crystallinity. CSP has the largest surface area, and CSL has the largest pore size. CSP is suitable for adsorbing oil molecules, and CSR can effectively remove antibiotics, especially at high concentrations $\left(10 \mathrm{mg} \mathrm{L}^{-1}\right)$, with capacities that can reach $1.067 \mathrm{mgg}^{-1}$. CSL has outstanding adsorption capacity for methylene blue, and CSL has outstanding adsorption capacity for methylene blue of $85.48 \mathrm{mg} \mathrm{g}^{-1}$. Pseudo-second-order kinetics better fit the process of adsorption of organic pollutants on the sample, indicating that the adsorption process is a chemical adsorption. The equilibrium adsorption data of sulfadiazine on CSR and CSL are consistent with the Langmuir isotherm model. The adsorption of sulfadiazine by CSP is more consistent with the Freundlich adsorption model, which proves that the adsorption is multilayered. The process of stover adsorption of oil requires multiple analyses. For the adsorption of $\mathrm{MB}$, the data are more consistent with the Langmuir isotherm model, that is, single-layer adsorption. The results of this work demonstrate that the breakdown of corn stover into its constituent fractions is an effective strategy for the adsorption of different organic pollutants and is conducive to the best use of all components of corn stover. In the future, we will further evaluate novel strategies for preparing modified materials derived from various parts of CS.

\section{Data Availability}

Data are available on request.

\section{Conflicts of Interest}

The authors declare that they have no conflicts of interest.

\section{Authors' Contributions}

Dan Peng conceived and designed the experiments; Dan Peng and Min Deng wrote the paper; Dan Peng and Fan Ouyang performed the experiments, measurements, and characterizations; Lei Nie reviewed and edited the paper; and Sifang Kong contributed to the analysis tools.

\section{Acknowledgments}

This work was supported by the National Natural Science Foundation of China (No. 42007323), the Natural Science Foundation of Guangdong Province (No. 2018A030313363), the Shenzhen Science \& Technology Project (No. SZIITWDZC2021A01, No. JSGG 20180504165551779), the
Open Fund of Guangdong Provincial Key Laboratory of Petrochemical Pollution Process and Control (No. 2018B030322017), the High-Level Professionals and Innovative Teams (No. SZIIT2019KJ024, No. SZIIT2019KJ007), and the Characteristic Innovation Project of Guangdong Universities (2019GKTSCX092).

\section{References}

[1] S. Mirshahghassemi, B. Cai, and J. R. Lead, "A comparison between the oil removal capacity of polymer-coated magnetic nanoparticles in natural and synthetic environmental samples," Environmental Science \& Technology, vol. 53, no. 8, pp. 4426-4432, 2019.

[2] F. M. Mtunzi, P. N. Diagboya, R.-A. Düring, and B. I. OluOwolabi, "Mesoporous SBA-15 functionalized with G-5 poly (amidoamine): a sustainable adsorbent for effective sequestration of an emerging aqueous contaminant," ACS Applied Nano Materials, vol. 4, no. 3, pp. 3052-3061, 2021.

[3] R. V. Xikhongelo, F. M. Mtunzi, P. N. Diagboya, B. I. OluOwolabi, and R.-A. Düring, "Polyamidoamine-functionalized graphene oxide-SBA-15 mesoporous composite: adsorbent for aqueous arsenite, cadmium, ciprofloxacin, ivermectin, and tetracycline," Industrial and Engineering Chemistry Research, vol. 60, no. 10, pp. 3957-3968, 2021.

[4] A. Sapkota, A. R. Sapkota, M. Kucharski et al., "Aquaculture practices and potential human health risks: current knowledge and future priorities," Environment International, vol. 34, no. 8, pp. 1215-1226, 2008.

[5] C. Yan, Y. Yang, J. Zhou et al., "Antibiotics in the surface water of the Yangtze estuary: occurrence, distribution and risk assessment," Environmental Pollution, vol. 175, pp. 22-29, 2013.

[6] Y. Zhang, D. Peng, Y. Luo, D. Huang, X. Guo, and L. Zhu, "Cellulase modified waste biomass to remove sulfamethazine from aqueous solutions," Science of The Total Environment, vol. 731, 2020.

[7] Y. G. Zhu, T. A. Johnson, J. Q. Su et al., "Diverse and abundant antibiotic resistance genes in Chinese swine farms," Proceedings of the National Academy of Sciences of the United States of America, vol. 110, no. 9, pp. 3435-3440, 2013.

[8] Q.-Q. Zhang, G.-G. Ying, C.-G. Pan, Y.-S. Liu, and J.-L. Zhao, "Comprehensive evaluation of antibiotics emission and fate in the river basins of China: source analysis, multimedia modeling, and linkage to bacterial resistance," Environmental Science \& Technology, vol. 49, no. 11, pp. 6772-6782, 2015.

[9] D. Peng, S. Cheng, H. Li, and X. Guo, "Effective multifunctional biosorbent derived from corn stalk pith for dyes and oils removal," Chemosphere, vol. 272, 2021.

[10] S. Hokkanen, A. Bhatnagar, and M. Sillanpaa, "A review on modification methods to cellulose-based adsorbents to improve adsorption capacity," Water Research, vol. 91, pp. 156-173, 2016.

[11] S. P. Onkani, P. N. Diagboya, F. M. Mtunzi, M. J. Klink, B. I. Olu-Owolabi, and V. Pakade, "Comparative study of the photocatalytic degradation of 2-chlorophenol under UV irradiation using pristine and Ag-doped species of $\mathrm{TiO}_{2}, \mathrm{ZnO}$ and ZnS photocatalysts," Journal of Environmental Management, vol. 260, 2020.

[12] C. Yu, D. Zeng, F. Chen et al., "Construction of efficient solarlight-driven quaternary $\mathrm{Ag}_{3} \mathrm{VO}_{4} / \mathrm{Zn}_{3}\left(\mathrm{VO}_{4}\right)_{2} / \mathrm{Zn}_{2} \mathrm{~V}_{2} \mathrm{O}_{7} / \mathrm{ZnO}$ 
heterostructures for removing organic pollutants via phase transformation and in-situ precipitation route," Applied Catalysis A: General, vol. 578, pp. 70-82, 2019.

[13] W. Li, B. N. Mu, and Y. Q. Yang, "Feasibility of industrial-scale treatment of dye wastewater via bio-adsorption technology," Bioresource Technology, vol. 277, pp. 157-170, 2019.

[14] C. Yang, S. Shang, and X. Y. Li, "Fabrication of sulfur-doped $\mathrm{TiO}_{2}$ nanotube array as a conductive interlayer of $\mathrm{PbO}_{2}$ anode for efficient electrochemical oxidation of organic pollutants," Separation and Purification Technology, vol. 258, 2021.

[15] E. Vaudevire, F. Radmanesh, A. Kolkman et al., "Fate and removal of trace pollutants from an anion exchange spent brine during the recovery process of natural organic matter and salts," Water Research, vol. 154, pp. 34-44, 2019.

[16] M. I. A. Abdel Maksoud, A. M. Elgarahy, C. Farrell, A.'. H. alMuhtaseb, D. W. Rooney, and A. I. Osman, "Insight on water remediation application using magnetic nanomaterials and biosorbents," Coordination Chemistry Reviews, vol. 403, 2020.

[17] X. Zhu, Y. Liu, C. Zhou, S. Zhang, and J. Chen, "Novel and high-performance magnetic carbon composite prepared from waste hydrochar for dye removal," ACS Sustainable Chemistry \& Engineering, vol. 2, no. 4, pp. 969-977, 2014.

[18] D. Peng, H. Li, W.-J. Li, and L. Zheng, "Biosorbent with superhydrophobicity and superoleophilicity for spilled oil removal," Ecotoxicology and Environmental Safety, vol. 209, 2021.

[19] H. Li, J. Xiong, G. Zhang et al., "Enhanced thallium(I) removal from wastewater using hypochlorite oxidation coupled with magnetite-based biochar adsorption," Science of The Total Environment, vol. 698, 2020.

[20] Y. Li, H. Li, F. Liu et al., "Zero-valent iron-manganese bimetallic nanocomposites catalyze hypochlorite for enhanced thallium(I) oxidation and removal from wastewater: materials characterization, process optimization and removal mechanisms," Journal of Hazardous Materials, vol. 386, 2020.

[21] B. Arnaud, S. Durand, M. Fanuel, F. Guillon, V. Mechin, and H. Rogniaux, "Imaging study by mass spectrometry of the spatial variation of cellulose and hemicellulose structures in corn stalks," Journal of Agricultural and Food Chemistry, vol. 68, no. 13, pp. 4042-4050, 2020.

[22] B. Zhang, W. Li, X. Xu et al., "Effect of aerobic hydrolysis on anaerobic fermentation characteristics of various parts of corn stover and the scum layer," Energies, vol. 12, no. 3, p. 381, 2019.

[23] D. Zhang, F. Wang, A. Zhang, W. Yi, Z. Li, and X. Shen, "Effect of pretreatment on chemical characteristic and thermal degradation behavior of corn stalk digestate: comparison of dry and wet torrefaction," Bioresource Technology, vol. 275, pp. 239246, 2019.

[24] H. Zhang, K. Chen, X. Gao, Q. Han, and L. Peng, "Improved thermal stability of regenerated cellulose films from corn (Zea mays) stalk pith using facile preparation with lowconcentration zinc chloride dissolving," Carbohydrate Polymers, vol. 217, pp. 190-198, 2019.

[25] M. Tang, R. Zhang, and Y. Pu, "Wheat straw modified with palmitic acid as an efficient oil spill adsorbent," Fibers and Polymers, vol. 19, no. 5, pp. 949-955, 2018.

[26] J. Pinto, D. Cruz, A. Paiva et al., "Characterization of corn cob as a possible raw building material," Construction and Building Materials, vol. 34, pp. 28-33, 2012.

[27] B. Doshi, M. Sillanpaa, and S. Kalliola, "A review of bio-based materials for oil spill treatment," Water Research, vol. 135, pp. 262-277, 2018.
[28] B. Biswas, N. Pandey, Y. Bisht, R. Singh, J. Kumar, and T. Bhaskar, "Pyrolysis of agricultural biomass residues: comparative study of corn cob, wheat straw, rice straw and rice husk," Bioresource Technology, vol. 237, pp. 57-63, 2017.

[29] S. K. Wiśniewska, J. Nalaskowski, E. Witka-Jeżewska, J. Hupka, and J. D. Miller, "Surface properties of barley straw," Colloids and Surfaces B: Biointerfaces, vol. 29, no. 2-3, pp. 131142, 2003.

[30] D. Li, F. Z. Zhu, J. Y. Li, P. Na, and N. Wang, "Preparation and characterization of cellulose fibers from corn straw as natural oil sorbents," Industrial \& Engineering Chemistry Research, vol. 52, no. 1, pp. 516-524, 2013.

[31] E. Pehlivan, T. Altun, and S. Parlayici, "Utilization of barley straws as biosorbents for $\mathrm{Cu}^{2+}$ and $\mathrm{Pb}^{2+}$ ions," Journal of Hazardous Materials, vol. 164, no. 2-3, pp. 982-986, 2009.

[32] F. Kallel, F. Chaari, F. Bouaziz, F. Bettaieb, R. Ghorbel, and S. E. Chaabouni, "Sorption and desorption characteristics for the removal of a toxic dye, methylene blue from aqueous solution by a low cost agricultural by-product," Journal of Molecular Liquids, vol. 219, pp. 279-288, 2016.

[33] R. Jothirani, P. S. Kumar, A. Saravanan, A. S. Narayan, and A. Dutta, "Ultrasonic modified corn pith for the sequestration of dye from aqueous solution," Journal of Industrial and Engineering Chemistry, vol. 39, pp. 162-175, 2016.

[34] M. Husseien, A. A. Amer, A. El-Maghraby, and N. Hamedallah, "A comprehensive characterization of corn stalk and study of carbonized corn stalk in dye and gas oil sorption," Journal of Analytical and Applied Pyrolysis, vol. 86, no. 2, pp. 360-363, 2009.

[35] Y. Jin, T. Huang, W. Geng, and L. Yang, "Comparison of sodium carbonate pretreatment for enzymatic hydrolysis of wheat straw stem and leaf to produce fermentable sugars," Bioresource Technology, vol. 137, pp. 294-301, 2013.

[36] S. Vafakhah, M. E. Bahrololoom, R. Bazarganlari, and M. Saeedikhani, "Removal of copper ions from electroplating effluent solutions with native corn cob and corn stalk and chemically modified corn stalk," Journal of Environmental Chemical Engineering, vol. 2, no. 1, pp. 356-361, 2014.

[37] G. D. Değermenci, N. Değermenci, V. Ayvaoğlu, E. Durmaz, D. Çakır, and E. Akan, "Adsorption of reactive dyes on lignocellulosic waste; characterization, equilibrium, kinetic and thermodynamic studies," Journal of Cleaner Production, vol. 225, pp. 1220-1229, 2019.

[38] L. Segal, J. J. Creely, A. E. Martin, and C. M. Conrad, “An empirical method for estimating the degree of crystallinity of native cellulose using the X-ray diffractometer," Textile Research Journal, vol. 29, no. 10, pp. 786-794, 1959.

[39] C. Aharoni and F. C. Tompkins, "Kinetics of adsorption and desorption and the Elovich equation," in Advances in Catalysis, D. D. Eley, H. Pines, and P. B. Weisz, Eds., pp. 1-49, Academic Press, 1970.

[40] L. Khezami and R. Capart, "Removal of chromium(VI) from aqueous solution by activated carbons: kinetic and equilibrium studies," Journal of Hazardous Materials, vol. 123, no. 1-3, pp. 223-231, 2005.

[41] M. H. A. Khatun, L. Wang, J. Zhao, and H. Chen, "Tissue fractionation of corn stover through steam explosion-assisted mechanical carding: its effect on enzymatic hydrolysis and pulping," Biomass and Bioenergy, vol. 122, pp. 109-116, 2019.

[42] S. Fan, Y. Sun, T. Yang et al., "Biochar derived from corn stalk and polyethylene co-pyrolysis: characterization and $\mathrm{Pb}$ (ii) 
removal potential," RSC Advances, vol. 10, no. 11, pp. 63626376, 2020.

[43] M. Wozniak, I. Ratajczak, D. Wojcieszak et al., "Chemical and structural characterization of maize stover fractions in aspect of its possible applications," Materials, vol. 14, no. 6, 2021.

[44] C. M. Navarathna, N. Bombuwala Dewage, C. Keeton et al., "Biochar adsorbents with enhanced hydrophobicity for oil spill removal," ACS Applied Materials \& Interfaces, vol. 12, no. 8, pp. 9248-9260, 2020.

[45] O. D. Bernardinelli, M. A. Lima, C. A. Rezende, I. Polikarpov, and E. R. deAzevedo, "Quantitative 13C MultiCP solid-state NMR as a tool for evaluation of cellulose crystallinity index measured directly inside sugarcane biomass," Biotechnology for Biofuels, vol. 8, no. 1, 2015.

[46] A. N. Ebelegi, N. Ayawei, D. Wankasi, E. D. Dikio, P. N. Diagboya, and F. M. Mtunzi, "Covalently bonded polyamidoamine functionalized silica used as a $\mathrm{Pb}$ (II) scavenger from aqueous solution," Journal of Environmental Chemical Engineering, vol. 7, no. 4, 2019.

[47] W. Huang, A. C. Wachemo, H. Yuan, and X. Li, "Modification of corn stover for improving biodegradability and anaerobic digestion performance by Ceriporiopsis subvermispora," Bioresource Technology, vol. 283, pp. 76-85, 2019.

[48] Y. Mei, Q. Che, Q. Yang et al., "Torrefaction of different parts from a corn stalk and its effect on the characterization of products," Industrial Crops and Products, vol. 92, pp. 26-33, 2016.

[49] W. Cao, Z. Wang, Q. Zeng, and C. Shen, " ${ }^{13}$ C NMR and XPS characterization of anion adsorbent with quaternary ammonium groups prepared from rice straw, corn stalk and sugarcane bagasse," Applied Surface Science, vol. 389, pp. 404-410, 2016.

[50] W. Cao, Z. Dang, X.-Q. Zhou et al., "Removal of sulphate from aqueous solution using modified rice straw: preparation, characterization and adsorption performance," Carbohydrate Polymers, vol. 85, no. 3, pp. 571-577, 2011.

[51] N. Liu, A. B. Charrua, C. H. Weng, X. Yuan, and F. Ding, "Characterization of biochars derived from agriculture wastes and their adsorptive removal of atrazine from aqueous solution: a comparative study," Bioresource Technology, vol. 198, pp. 55-62, 2015.

[52] R. Han, L. Zhang, C. Song, M. Zhang, H. Zhu, and L. Zhang, "Characterization of modified wheat straw, kinetic and equilibrium study about copper ion and methylene blue adsorption in batch mode," Carbohydrate Polymers, vol. 79, no. 4, pp. 1140-1149, 2010.

[53] V. C. Srivastava, M. M. Swamy, I. D. Mall, B. Prasad, and I. M. Mishra, "Adsorptive removal of phenol by bagasse fly ash and activated carbon: equilibrium, kinetics and thermodynamics," Colloids and Surfaces A: Physicochemical and Engineering Aspects, vol. 272, no. 1-2, pp. 89-104, 2006.

[54] S. E. Elhafez, H. A. Hamad, A. A. Zaatout, and G. F. Malash, "Management of agricultural waste for removal of heavy metals from aqueous solution: adsorption behaviors, adsorption mechanisms, environmental protection, and technoeconomic analysis," Environmental Science and Pollution Research International, vol. 24, no. 2, pp. 1397-1415, 2017.

[55] L. Y. Gao, J. H. Deng, G. F. Huang et al., "Relative distribution of $\mathrm{Cd}^{2+}$ adsorption mechanisms on biochars derived from rice straw and sewage sludge," Bioresource Technology, vol. 272, pp. 114-122, 2019.
[56] X. Liu, J. Tian, Y. Li et al., "Enhanced dyes adsorption from wastewater via $\mathrm{Fe}_{3} \mathrm{O}_{4}$ nanoparticles functionalized activated carbon," Journal of Hazardous Materials, vol. 373, pp. 397407, 2019.

[57] L. Oliveira, J. Saleem, A. Bazargan, J. Duarte, G. McKay, and L. Meili, "Sorption as a rapidly response for oil spill accidents: a material and mechanistic approach," Journal of Hazardous Materials, vol. 407, 2021.

[58] Y. Xiang, X. Yang, Z. Xu et al., "Fabrication of sustainable manganese ferrite modified biochar from vinasse for enhanced adsorption of fluoroquinolone antibiotics: effects and mechanisms," Science of The Total Environment, vol. 709, 2020. 